\title{
Salinalona gen. nov., an euryhaline chydorid lineage (Crustacea: Branchiopoda: Cladocera: Anomopoda) from the Oriental region
}

\author{
Kay VAN DAMME, ${ }^{1 *}$ Supiyanit MAIPHAE ${ }^{2}$ \\ ${ }^{1}$ Environmental Genomics Group, School of Biosciences, University of Birmingham, B15 2TT Edgbaston, Birmingham, UK; ${ }^{2}$ Plank- \\ ton Research Unit, The Center of Excellence for the Biodiversity in Peninsular Thailand, Department of Biology, Prince of Songkla \\ University, 90112 Hat Yai, Thailand \\ *Corresponding author: kay.vandamme@gmail.com; k.p.vandamme@bham.ac.uk; supiyanit.m@psu.ac.th
}

\begin{abstract}
Until now, a single endemic cladoceran genus was known from the Oriental region. We propose the region's second endemic lineage of generic rank, Salinalona gen. nov., to accomodate the South East Asian Alona sarasinorum Stingelin, 1900 and the Indian A. taraporevalae Shirgur and Naik, 1977. Morphological revision shows that the external similarities with Alona Baird, 1843 or Leberis Smirnov, 1969 and Celsinotum Frey, 1991 that have been proposed in the past, are the result of convergence. The small lineage is euryhaline, even halophylic, an unusual adaptation in the order Anomopoda and particularly in the family Chydoridae. We discuss the position and adaptation of Salinalona gen. nov., such as a strongly modified hook on the first limb, based on a detailed study of populations from Maikhao peat swamp, Phuket island, Thailand. We include comparative notes on the circumtropical genus Euryalona Sars, 1901, with detailed morphology of the Asian E. orientalis (Daday, 1898). A key to all species of both genera is included.
\end{abstract}

Key words: Salinalona gen.nov., Euryalona, Alona sarasinorum, Chydoridae, Cladocera, Southern Thailand.

Received: February 2013. Accepted: June 2013.

\section{INTRODUCTION}

Progress in biodiversity, evolution and biogeography of freshwater invertebrates in any given region are based on firm systematics. In the Cladocera (Crustacea: Branchiopoda), which is one of the main microcrustacean groups in freshwater ecosystems, taxonomy often forms a bottleneck for applied research. The latter problem is being challenged in South East (SE) Asia by an increased intensity of taxonomical output during the last decades, in which Thailand takes a regional lead, currently being a $h u b$, having more skilled specialists and more updated cladoceran systematics than most Western countries (Van Damme et al., 2013; Korovchinsky, 2013; Kotov et al., 2013). There is no doubt that in Southern Asia, or in fact, in the large Oriental region, a lot remains to be discovered, yet there is a significant diversity to be re-discovered among existing records and taxa. Improving cladoceran systematics by tackling taxa one at a time, brings stepwise progress, whereas large revisions and local faunistic studies allow leaps forward. In some cases, the revision of a known taxon can lead to the discovery of a new lineage.

Stingelin (1900) described Alona sarasinorum Stingelin, 1900 as a new species from Celebes (Sulawesi, Indonesia). The specimens were collected by Dr. Fritz and Dr. Paul Sarasin in 1895, from a single coastal locality near the city of Makassar. Stingelin (1900) reported a low diversity (three copepods, two ostracods and three cladocerans) and wrote that, judging from the species composition, it was most likely taken from the shore of a shallow, muddy freshwater pond: Aus dieser Zusammensetzung des Materials und dem Ueberwiegen plumper, schwerfälliger Ostracoden, geht hervor, dass dieser Fang dem Strande eines seichten, schlammigen Süsswasserteiches entnommen wurde. Like A. sarasinorum, the two other cladoceran species that Stingelin (1900) found in the sample, were euryhaline (Moina macrocopa (Straus, 1820), Diaphanosoma celebensis Stingelin, 1900). Since then, A. sarasinorum has been reported sporadically from freshwater to brackish/saline pools in the region, from India to Indonesia (Brehm, 1933; Idris and Fernando, 1981; Idris, 1983; Ventakaram, 1999; Maiphae et al., 2008). Brehm (1933) mentioned the species briefly and Frenzel (1987) made a short note and a few drawings of the holotype, confirming its validity and depicting the conspicuously large hook on the female's first limb (from the collection at the Naturmuseum Olten, Switzerland, where the collection of Theodore Stingelin is kept). Perhaps unaware of Stingelin's taxon at the time, Shirgur and Naik (1977) described Alona taraporevalae Shirgur et Naik, 1977 based on ephippia collected from high salinities (26\% or $26 \mathrm{ppt}$ ) at Back bay near Bombay (now Mumbai), India (Sharma and Michael, 1984; Michael and Sharma, 1988; Frey, 1991). The latter is now considered a likely junior synonym of $A$. sarasinorum (Maiphae, 2005; Van Damme et al., 2010), even though speciation and isolation could be possible (it is a long way 
from Makassar to Mumbai). We re-address the validity of the latter taxon here. The validity of $A$. sarasinorum itself was never at stake, as the species was never listed as an incertae sedis, nor synonymised (Smirnov, 1974). In fact, Stingelin's (1900) drawings are clear and allow an easy recognition. The relationships are less clear, and the author suggested a resemblance with $A$. intermedia Sars, 1862: Dieser Lynceide tritt in seinem ganzen Habitus der Alona intermedia Sars am nächsten. Er ist jedoch grösser als die weit verbreitete SARS'sche Art. Seine Länge beträgt 0,460,52 mm., die Höhe 0,36-0,38 mm. Ausserdem zeigten sich bei eingehender Betrachtung eine Anzahl wesentlicher Verschiedenheiten, welche mich bestimmten eine neue Art aufzustellen. The resemblance with A. intermedia is definitely outdated. Frey (1991) compared A. taraporevalae with Celsinotum Frey, 1991 and with A. diaphana King, 1853 , which have a similar postabdomen morphology, and he included a set of drawings (A. diaphana was later separated from Alona and moved to Leberis Smirnov, 1969) (Sinev et al., 2005; Van Damme et al., 2010). Prof. Frey was particularly interested in this chydorid because it inhabits saline waters (Frey, 1991; Shirgur and Naik, 1977) and because it looks superficially like Celsinotum (also euryhaline) and $A$. diaphana, even having a faint dorsal keel. He concluded: Nevertheless, it should be apparent that this taxon is completely different from both Alona diaphana and the species of Celsinotum. Because the species was not the main focus of Frey's study and Alona remained poorly understood, no decision was made on the position of A. taraporevalae. A. sarasinorum was, surprisingly, not mentioned by Frey (1991). On the peculiar hook on the first limb of A. taraporevalae, Frey (1991) wrote It is as if the entire morphology of the species has been modified for the functioning of the trunklimb hook, which is somewhat reminiscent of the very strong hook in Euryalona. Indeed, Alona sarasinorum (Frenzel, 1987), Alona taraporevalae (Frey, 1991) and Euryalona Sars, 1901 (Rajapaksa and Fernando, 1987; this study) have a modified hook on the first thoracic limb pair. Further relationships between the latter taxa ( $E u$ ryalona and A. taraporevalae/A. sarasinorum) were never explored in detail. In fact, Euryalona Sars, 1901, which is relatively common in tropics/subtropics, is another Aloninae genus of which the description of the detailed limb morphology has not been updated. The last revision of morphology in this genus dates to Rajapaksa and Fernando (1987) and the latest useable key to Smirnov (1974).

The question is not whether A. sarasinorum in itself is a valid species, but whether it belongs to Alona and if not, where it is situated in the Aloninae. Examining peculiar taxa is important for our understanding of the diversity and the evolution of the Aloninae, yet this has only become possible since the recent revisions in Alona. Our definition of the core of this lumping genus and the resolution of morphology of the adult parthenogenetic fe- males, has advanced when compared to just a decade ago (Van Damme and Dumont, 2008a, 2008b; Van Damme et al., 2010). Maiphae (2005) produced the first detailed descriptions [limb drawings and scanning electron microscopy (SEM) of the limbs of adult parthenogenetic $A$. sarasinorum females from Phuket] and studied the holotype. The genus Alona was not understood in the way it is now and the observations and drawings in Maiphae (2005) were never published (until this study). The idea at the time was that the detailed description of the adult parthenogenetic females of the Thai $A$. sarasinorum, had risen the amount of data on this taxon to a higher level, but that it did not allow a final conclusion on its phylogenetic position (Maiphae, 2005) and that $A$. taraporevalae is most likely a synonym (Maiphae, 2005). Now, these morphological characters and observations can be re-assessed and placed within a wider context. Several notes, illustrations and all the SEM photographs that were compiled as part of the PhD dissertation of Maiphae (2005), carried out in collaboration between the Prince of Songkla University (Thailand) and Ghent University (Belgium), are presented herein for the first time.

This study aims to redescribe and to situate Stingelin's rare A. sarasinorum, based on specimens from Southern Thailand. We propose its assignment to a new genus and provide, in addition, comparative notes on the genus $\mathrm{Eu}$ ryalona. The sampling in Southern Thailand is part of long-term, continuing surveys by the Plankton Research Unit at the Center of Excellence for the Biodiversity in Peninsular Thailand, Prince of Songkla University (PSU), Thailand. Earlier studies within the same project (or theme, leading to a series of projects) have lead to updates on Thai cladoceran diversity (Maiphae et al., 2008) and to the finding of new species in habitats that are often ignored in tropical surveys, such as swamps and peat swamps (Van Damme et al., 2013). The current study involves specimens from peat swamps as well. We explore the morphology of A. sarasinorum to examine the question whether it is indeed an Alona, and if not, where in the Aloninae this taxon is situated, while at the same time revisiting the validity of $A$. taraporevalae. The study is part of long-term taxonomical revisions and biodiversity research in SE Asia, as well as of the ongoing global revision of Alona, which is aimed to increase our knowledge on the biogeography, the diversity and the evolution of the Chydoridae.

\section{METHODS}

Samples from Maikhao peat swamp, Phuket province, southwestern Thailand (Van Damme et al., 2013), from Pattani bay, Yaring estuary (Pattani province, southeastern Thailand), from Pak Panang bay (Nakornsrithamaras province, southeastern Thailand) and from the small swamp at Rawi island (southwestern Thailand) were taken 
using a conical plankton net (mesh size $60 \mu \mathrm{m}$ ). Specimens were fixed in $4 \%$ formaline. After that, specimens were sorted with a stereo microscope (Olympus SZ-40; Olympus, Center Valley, PA, USA). The morphological characters were examined using an Olympus $\mathrm{CH}-2$ (Olympus) compound microscope. Completed and dissected specimens were prepared on permanent glass slides. They were put in glycerin, mixed with few drops of formaldehyde. Before the specimens were mounted, small pieces of clay (plasticin) were placed in each corner of the cover slip in order to protect them from deformation. The cover slide was then sealed with nail varnish and later with more permanent varnish. Drawings were made from completed and dissected specimens using a camera lucida connected to the compound microscope. The specimen preparation is described in Maiphae (2005) and Van Damme et al. (2013); in the latter also more information and a map are shown on the main locality (Maikhao peat swamp). Scanning electron microscopy photographs were taken using a JSM-5800LV, JEOL SEM at PSU (Thailand). Specimens from field samples were cleaned, identified and dehydrated in a series of increasing alcohol concentrations, per 10\% (10-100\%) of ethanol. Dehydration series were performed twice per concentration, each time $30 \mathrm{~min}$, with extended steps around $95-96 \%$. Then, the specimens processed using critical point drying (CPD), mounted on $10 \mathrm{~mm}$ stubs and coated with gold. Specimens that were studied at Ghent University, Belgium, have been moved with the collection to the Royal Belgian Institute for Natural Sciences (RBIN), Brussels, Belgium, under the accession number RBIN INV IG 32.094 (for the complete collection), which is in the process of being catalogued (F. Fiers, personal communication). All Thai material is deposited and kept at the Princess Maha Chakri Sirindhorn Natural History Museum, Faculty of Science, Prince of Songkla University, Thailand (PSUNHM).

\section{Study site: Maikhao peat swamp, Phuket island}

The main populations of $A$. sarasinorum on which this study is based, derive from Maikhao (also Mai-Khao or Mai Khao) peat swamp, nominated a protected area in Maikhao subdistrict, Thalang district, Phuket province, Thailand. The Maikhao peat swamp is one of Phuket's remaining peat swamps along the Maikhao coast, which were historically connected but later became fragmented as a result of human impact (APFP, 2010-2013; Chittapun et al., 2005). The original area of the complete Phru Ban Maikhao peat swamp forest was ca. 40.3 ha which formed one large swamp, but is currently divided into at least ten smaller patches by development and now make up the last remaining peat swamp habitats in Phuket (APFP, 20102013). Studies on zooplankton have been carried out on the swamp behind the Maikhao temple. This site was a pristine freshwater swamp, receiving some saltwater infiltration at times being separated by just a dike from the Andaman sea (Segers and Chittapun, 2001). This covers about $0.056 \mathrm{~km}^{2}$ (APFP, 2010-2013). During the last decade, the salinity of the swamp increased due to human interference through shrimp farming (APFP, 2010-2013), as it received discharged saltwater from nearby aquaculture farming (Chittapun et al., 2005). Among zooplankton, the rotifers of this particular peat swamp have been studied intensively, indicating high species diversities, with Maikhao peat swamp harbouring about $69 \%$ of the total rotifer diversity known from Thai peat swamps at the time (2005) and functioning as an important locality for a number of new records and new species (Chittapun et al., 1999, 2005, 2007; Segers and Chittapun, 2001). In Cladocera, the situation is the same, this site having a significant diversity and containing new records (Maiphae et al., 2008; Van Damme et al., 2013). Tropical peat swamps in general can be considered as important habitats for cladoceran diversity and speciation (Van Damme et al., 2013). Most recently, Maikhao peat swamp has been further affected by changes, especially after 2005 (see Discussion). Most of the other swamps on Phuket of this area have been dredged, converted to land, polluted or turned into ponds or reservoirs (APFP, 2010-2013).

\section{RESULTS}

\section{Taxonomic account}

\section{Family Chydoridae Dybowski \& Grochowski, 1894}

\section{Subfamily Aloninae Dybowski \& Grochowski, 1894 emend. Frey, 1967}

\section{Genus Salinalona gen. nov.}

Type species: Salinalona sarasinorum (Stingelin, $1900)=$ Alona sarasinorum Stingelin, 1900. We recognise two species here, Salinalona sarasinorum comb. nov. (Stingelin, 1900) and Salinalona taraporevalae comb. nov. (Shirgur and Naik, 1977).

Etymology: from saline and Alona, referring to the tolerance of both species in this lineage to saline conditions.

Diagnosis of the genus: adult parthenogenetic females. Body ovoid, weakly expressed dorsal keel present. Reticulation poorly expressed, carapace granulate appearance. Posterodorsal angle of the valves not expressed and low. Posteroventral angle not angular but round, without denticles. Ventral margin strongly convex and with spiniform setae, implanted just submarginally. Head relatively small with low wide rostrum. Three main head-connected head pores and two lateral simple small pores in shallow depressions. Labral keel short and convex with small ventral indentation and with rows of small setules and no lateral horns. Intestine with at least two loops. Abdomen without abdominal projections. Postabdomen about 2.5- 
2.75 times as long as wide. Anus in middle part of the postabdomen, margin concave, preanal margin small but present, postanal margin angular. Dorso-distal angle not expressed, embayment weak or absent. Marginal denticles large and single, not on a joint basis, but more or less arranged in groups of about three denticles each, in total about ten. Lateral fascicles short, not or just reaching beyond the margin. Terminal claws (postabdominal claws) evenly bent. Single basal spine large, reaching between one third to up to almost half the terminal claw length. Antennules short and stout with sensory seta on a projection and aesthetascs all apical, two a bit longer than others, the shortest ones about half as long as antennular corm length or just longer, sensory seta about at a third from the antennular tip. Antennal formula 001/101 for spines and 113/003 for setae. Lateral setae present, apical setae normal and long. Antennal spines all very short. First maxilla with two setae. Five limb pairs. Epipodites short and round without projections. First limb (P1) with strongly developed hook-like seta on the inner distal lobe (IDL). External accessory seta absent, outer distal lobe (ODL) with one long seta, IDL with three setae (one hook). En1 with two setae, en2 with three setae and en3 with four setae, anterior soft elements reduced. Exopodite II without a seta. Endopodite II with eight scrapers decreasing in size towards gnathobase and with sixth scraper with stronger denticles. Remainder of soft setae on second limb (P2) present between third and fourth scrapers. Filter plate II with seven setae of which first two smaller. Gnathobase II with three elements on a slightly elevated basis. Exopodites III to V small. Exopodite III with six setae. Endopodite III with four soft setae, filter plate III with seven setae. All setae on endopodite III well developed. Exopodite IV with six setae. Endopodite IV with flaming torch setae not strongly modified. Inner row with three setae, marginal row with four setae and filter plate IV with five setae. Exopodite V with four setae of which the last is very short. Two inner setae. Filter plate V absent, only two reduced elements. Limb VI absent and no rudiment present. Ephippial female unstudied. Adult male with strongly narrowed postabdomen and projections for the sperm ducts and antennule with lateral aesthetascs.

\section{Description of species}

\section{Salinalona sarasinorum (Stingelin, 1900) comb. nov.}

Alona sarasinorum in Stingelin (1900); Brehm (1933); Smirnov (1974); Frenzel (1987). As Alona cf. sarasinorum in Idris and Fernando (1981); Idris (1983).

Specimens examined: China - Numerous specimens from a small swamp in Zhuhai City collected 31-07-2010 and from Qi Ao island, Guangdong province, China, collector (coll.) unknown. Indonesia - Holotype - Loc. muddy shallow water near the city of Makassar, Sulawesi, Indonesia; coll. Dr. Fritz and Dr. Paul Sarasin, 1895 (Stingelin, 1900). Specimen from the Collection Th. Stingelin, NMO, Switzerland, Holotype, Slide III/6 (see Frenzel, 1987). Thailand - Ten specimens from Maikhao peat swamp, Phuket province, southwestern Thailand $\left(8^{\circ} 07.21^{\prime} \mathrm{N}\right.$, $98^{\circ} 17.34^{\prime} \mathrm{E}$ ), pH 6.89, dissolved oxygen (DO) 6.9, conductivity 7.28 and salinity $0.3-0.5 \mathrm{ppt}$ (measurements at first date of collection), collected 27-10-2001 by Dr. Supiyanit Maiphae (SM). Additional specimens raised from dried mud collected from the same locality on April 2000 by SM and Dr. Kay Van Damme (KVD). Specimens from Maikhao peat swamp are deposited at the Princess Maha Chakri Sirindhorn Natural History Museum (PSUNHM), Faculty of Science, Prince of Songkla University, Thailand. One adult parthenogenetic female, in a slide, from Maikhao peat swamp, Phuket province, western coast of southern Thailand, coordinates $8^{\circ} 07.21^{\prime} \mathrm{N} 98^{\circ} 17.34^{\prime} \mathrm{E}$, coll. by $\mathrm{S}$. Maiphae, 27.X.2001. Accession number PSUZC-PK100301, labeled as Salinalona sarasinorum (Stingelin, 1900) comb. nov. one parthenogenetic female from Maikhao peat swamp, Phuket province, South Thailand. Additional material: one complete adult parthenogenetic female, in slide, same data as previous specimen. Accession number PSUZC-PK1003-02. Three additional adult parthenogenetic females (with same data as previous specimens) in a tube with 70\% ethanol, deposited under PSUZC-PK100303. Other (wet) samples and slides for this study, are kept at the Plankton unit at PSU, Thailand: four specimens from Pattani bay, Yaring estuary, Pattani province, southeastern Thailand, pH 7-8, salinity 6-8 ppt, collected in 2006 by S. Mulmek. Few specimens from Pak Panang bay, Nakornsrithamaras province, southeastern Thailand, collected in 2005 by S. Fangcholjit. Few specimens from a small swamp, Rawi island, southwestern Thailand, collected May 2011 by SM and P. Saardrit.

Adult parthenogenetic females: Habitus (Fig. 1A, details in Fig. 2, SEM in Figs. 3a, 3b). Moderately sized chydorid, 0.35-0.48 mm, average $0.4 \mathrm{~mm}$. Stingelin (1900) noted $0.46-0.52 \mathrm{~mm}$ for his population from Celebes. In life, relatively dark brown to orange colour. Ornamentation see under Carapace. Body 1.3 times as long as high, height $0.24-0.3 \mathrm{~mm}$. Body shape ovoid, in lateral view oval to fusiform, tapering distally, with convex posterior margin and no clear posterodorsal corner; the latter low, at about one quarter from the maximum body height (Fig. 1A). Dorsum convex, maximum height of body near the middle (Fig. 1A). In dorsal view (Fig. 3b), body bilaterally compressed but not flattened, with widest part near middle. A moderately expressed dorsal keel or carina is present (Fig. 3b). The posteroventral corner of the valves (Fig. 2E) is round to broad angular, with short, thick setules, which are not arranged in clusters. See more under Carapace in next paragraph. 
Head. The head is rather frontal and high in lateral view (Fig. 1A), the headshield connecting at about one fifth of the total body length. Ocellus and eye of similar sizes, the centre of the ocellus equidistant between centre of the eye and the rostrum (Fig. 1A). Rostrum blunt, round and broad, antennular corms shorter than the rostral tip (Fig. 1A), aesthetascs just reaching beyond it (Fig. 3a). The headshield is rather rectangular and the rostrum is rather straight in dorsal view, no wide lateral projections on the headshield (Idris and Fernando, 1981). Three main connected head pores and two lateral pores (Figs. 1C, 3c, $3 d)$. The lateral pores are about the same distance from the midline as the distance between the first and last main headpores and postpore distance $(\mathrm{PP})=$ about one interpore distance (IP).

Carapace. Light brown, transparent. Ornamentation

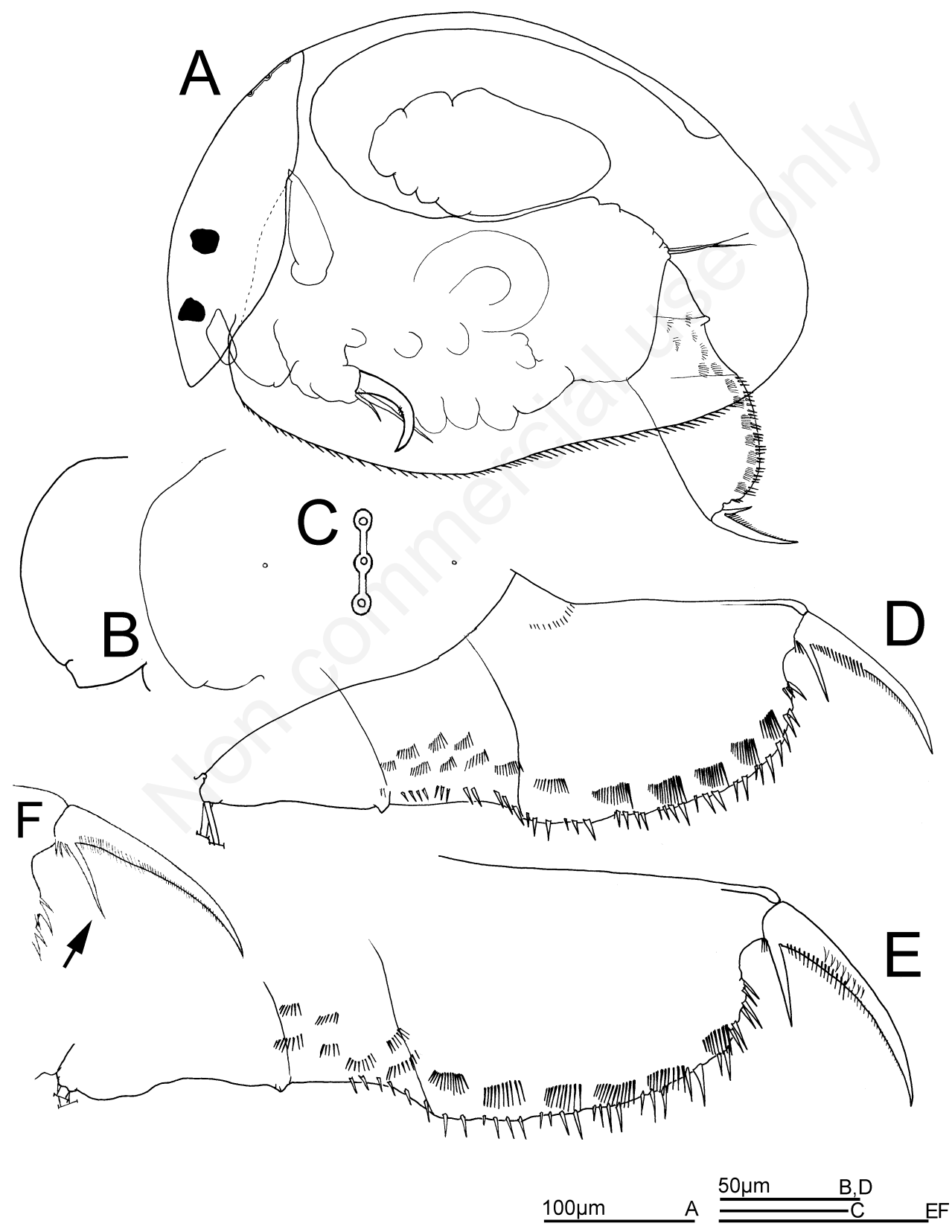

Fig. 1. Salinalona sarasinorum (Stingelin, 1900), adult parthenogenetic female from Maikhao swamp, Phuket island (Phuket province), Thailand, coll. by S. Maiphae, 27.X.2001. A) Habitus, lateral view; B) labral keel, lateral view (+variation); C) head pores, dorsal view; $\mathrm{D}, \mathrm{E})$ postabdomen; F) terminal claw (arrow points at basal spine). 
not expressed, except in anterior region of the carapace, below the head, with longitudinal striae that parallel the frontal carapace margin (Fig. 3a). When present on the rest of the carapace, only seen by faint wide striae or faint hexagons. Carapace may have a granulate appearance. Anterior margin of the valve with faintly expressed flange (Fig. 2D). Marginal setae 58-70, average about 65 (Fig. 1A), in two groups, one longer towards the ventral embayment, then shorter by half to one third (Fig. 3i). All the marginal setae are spiniform and bear no lateral setules, and are implanted submarginally on the inside of the valve (Fig. 2E, arrow; Fig. 3i). Towards the end of the posteroventral corner of the valves, the setae remain spiniform and are small, but do not clearly decrease in size, they rather stop abruptly and continue in a row of spinules along the inner margin that continues towards the dorsum (Fig. 2E).

Labrum (Figs. 1B and 3e) rather short and round. Labral keel in lateral view with convex and angular ventral corner, with rows of minute setules along the labrum, not visible under light microscopy (Fig. 3e). There are no lateral horns. The labrum has a clear indentation below (Fig. 1B, left), and the lower tip is protruding.

Antennules (Fig. 2A). Relatively short and wide, about two times as long as wide. The sensory seta is situated at $c a$. one third from the apex and on a clear projection (Fig. $2 \mathrm{~A}$, arrow). No setules were observed on the antennular body under light microscopy (yet not studied under SEM). Aesthetascs of similar size, two are slightly longer. The shorter aesthetascs are about half the length of the antennular body. Second antennae (Figs. 2B, 2C, 3f) with relatively short, wide endopodite and exopodites (en>ex). Coxal spine long (Fig. 3f). Spinal formula 001/101, setal formula 113/003. The first endopodite seta reaches just beyond the ultimate segment of the endopod (Fig. 2B and $2 \mathrm{C}$ ), the second endopodite seta is longer than the length of complete endopodite. The exopodite has a short spine on the first segment, that does not reach half of the second exopodite segment (Fig. 2C). Terminal or apical spines on exo- and endopodite are also short, not longer than half the lengths of the (ultimate) segments on which they are implanted. The apical exopodite spine is slightly larger than the apical endopodite spine (Figs. 2C and 3f). Small rows of denticles on the antennular segments, nearly not visible under light microscopy (Fig. 3f). Terminal antennal setae are all fine, long and of similar thickness (Fig. 2B).

Postabdomen (Figs. 1D, 1E, 3g, 3h) long, and deepest at the postanal projection. No deep dorso-distal embayment near the base of the terminal claw, but a shallow embayment is present. Length varies, about 2.5 to 2.75 times as long as

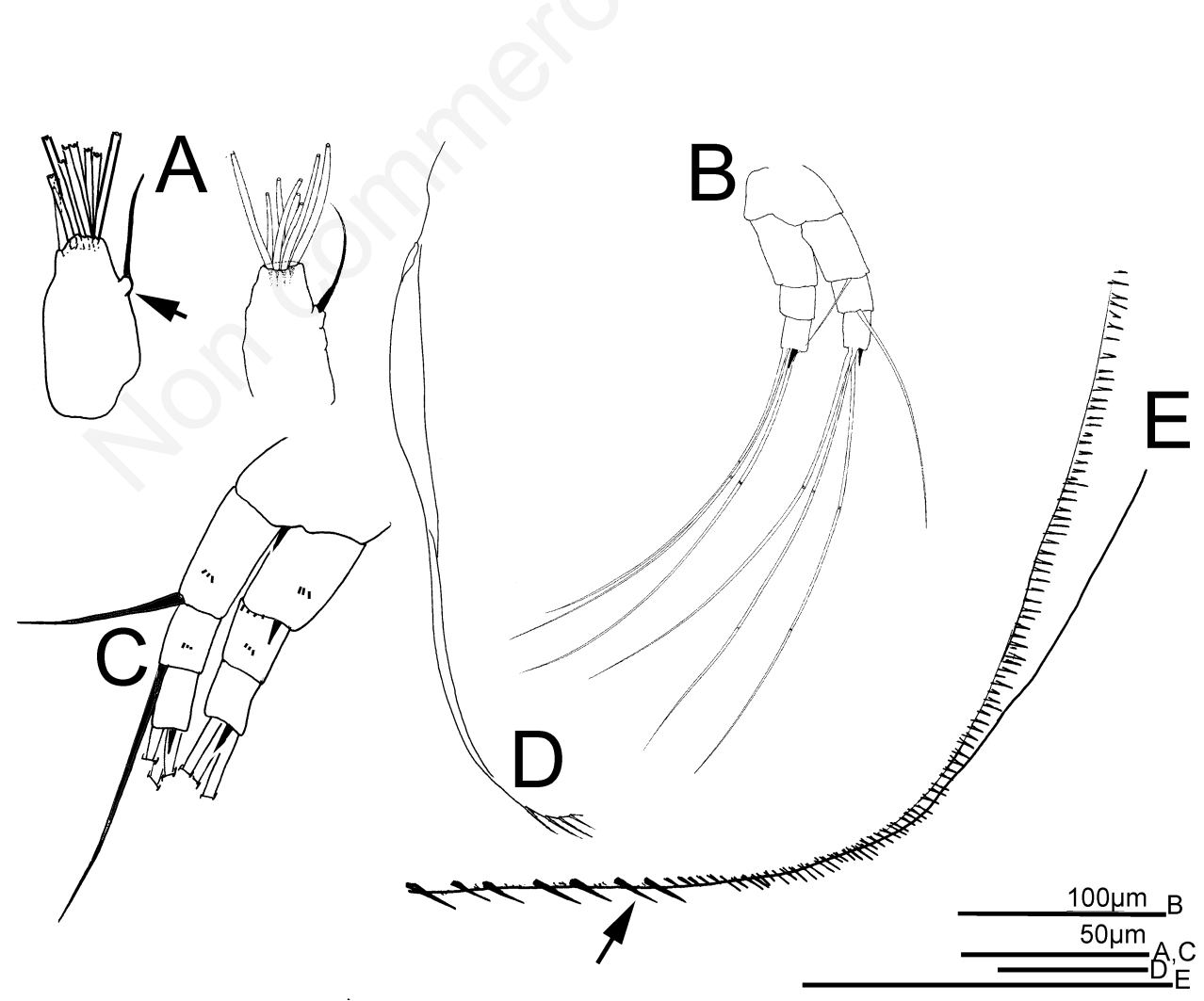

Fig. 2. Salinalona sarasinorum (Stingelin, 1900), adult parthenogenetic female from Maikhao swamp, Phuket island (Phuket province), Thailand, coll. by S. Maiphae, 27.X.2001. A) First antenna (arrow on projection); B) second antenna; C) second antenna (apical setae truncated); D) carapace frontal margin; E) carapace posteroventral corner (arrow on setules). 

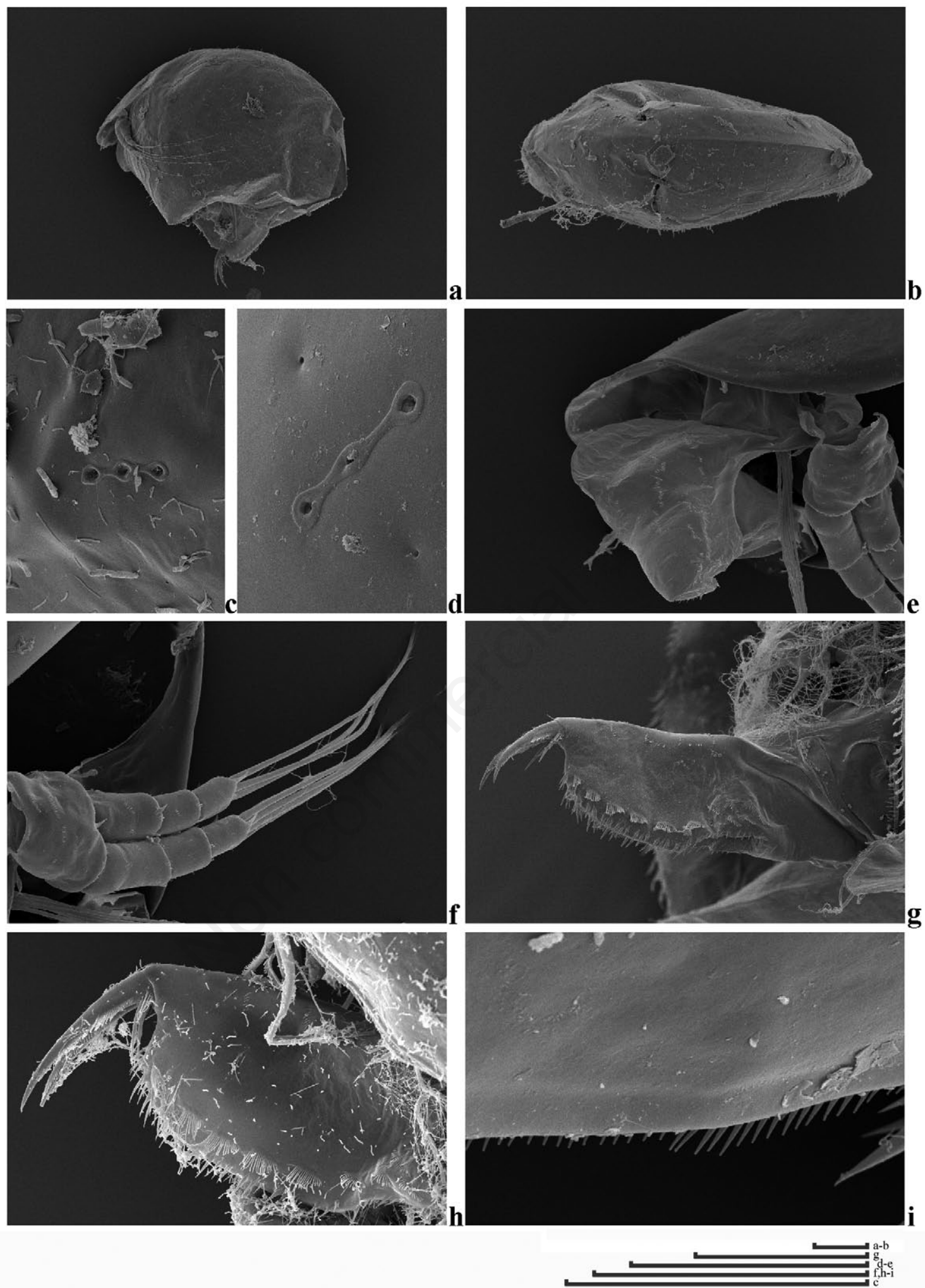

Fig. 3. Salinalona sarasinorum (Stingelin, 1900), adult parthenogenetic female from Maikhao swamp, Phuket island (Phuket province), Thailand, coll. by S. Maiphae, 27.X.2001. Scanning electron microscopy of external features and postabdomen. a) Habitus, lateral view; b) habitus, dorsal view (with faint carina or dorsal keel); c,d) head pores; e) labral keel; f) second antenna; g,h) postabdomen; i) ventral carapace setae. Scale bars $=100 \mu \mathrm{m}$. 
wide, gently tapering distally (Fig. 1D and 1E). Ventral margin straight, as long as the anal and preanal margins together. Postanal margin about (or just longer than) twice the length of the anal margin and preanal margin about as long or just longer than anal margin (in fact, postanal margin is about same length as anal and preanal margins together). The dorsodistal margin is not strongly protruding and does not reach beyond the basis of the terminal claw. The preanal corner is well developed, and the postanal corner is clear but not strongly expressed (Fig. 1D). The anal margin is straight for most its length and bends distally towards the postanal corner (Fig. 1E). Postabdominal armature. There are about nine to ten groups of large separate teeth on the postanal margin (Figs. 1D, 1E, 3g). These marginal teeth are long and stout and form a nearly continuous row, yet between each group of two to four (mostly three) stout, large teeth, there is a short space in between. In each group of a few spines, the distal one is the largest, best visible on SEM (Fig. $3 \mathrm{~g}$ ). In total, there are about ten of these groups along the postanal margin. Lateral fascicles about six to seven groups in the postanal region, each group similar with about eight to eleven spinules, which are not strongly differentiated in thickness, and which are gradually increasing in size (within a group) distally. The lateral fascicles rarely reach over the dorsal postanal margin (Figs. 1D, 3g, 3h), if they do, there are very few and they do not reach over by more than half (or mostly one third) of their lenghts (Fig. 1E). A few rows of very short denticles are present near the ventral margin in the postanal portion (Figs. 1D and 3g). In the anal margin, the lateral fascicles form two to three rows of small groups of spinules (Fig. 1D and 1E), the marginal denticles are represented by smaller teeth that form up to four groups (Fig. 1D) or a continuous row (Fig. 1E). Terminal claw (Figs. 1F, $3 \mathrm{~g}, 3 \mathrm{~h}$ ). Longer than the anal margin (about 1.5 times as long), curved and narrowing distally. Strong proximal pecten present that reaches about half the claw (Fig. 3h) and is followed by a finer, distal pecten with shorter spinules (Fig. 1E). The spinules of the proximal pecten are protruding forward distally (Fig. 3h). The basal spine is long, up to half the length of the terminal claw and at least two times the thickness of the terminal claw at its basis. Basal spinules present and visible, but no longer than one fourth or one fifth of the basal spine length (Figs. $1 \mathrm{~F}$ and $3 \mathrm{~h}$ ).

Five pairs of limbs (Figs. 4-8). First maxilla with two bent large setae with fine setules (Fig. 5D).

First limb (Figs. 4 and 5A-C). Epipodite not seen. First endite with two long apical setae (Fig. 5A) and one small anterior reduced seta (Fig. 5B), second endite with three setae, of which one distinctly longer (Fig. 5A) and one additional small anterior element (Fig. 5B), third endite with four setae with relatively similar thickness (Figs. 4a and $5 \mathrm{~A}$ ); anterior elements on en 1-2 present yet strongly reduced, as stated (Fig. 5B). Outer distal lobe has a slender single seta, setulated in the distal half to two thirds and longer than the largest IDL seta (Fig. 5C). The IDL has three setae, of which one is strongly modified into a large hook (Figs. 4a-e, 5A, 5C). The structure is shown best in Fig. 4e and drawn in Fig. 5C. This hook-like seta is very thick and ends sharply, bent strongly in its distal fourth. Along the inner margin up to near the middle, there is a row of minute denticles (Fig. 4e). The structure is clearly visible in the animal without dissection (Fig. 1A). The two other IDL setae are typical, fine setae, one shorter one longer (1.5-two times as long as the shortest one), and with long setules in distal half, the longest seta therefore has a scraper-like appearance (Figs. $4 \mathrm{~b}$ and $5 \mathrm{C}$ ). At the basis of the IDL, there is a large group of spinules (Fig. $4 \mathrm{e})$. The thickness of the hook at base, is about a fourth of its length. The limb corm has anterior setule groups, five to seven groups (Figs. 4a, 4c, 5A). These groups are on clear (pseudosegmental) projections (Fig. 4a and 4c). Ejector hooks (Fig. 4b and 4g) rather long, one longer than the other and unilaterally armed with long spinules on the distal half (Fig. 4g). Note: we noted two apical, peculiar structures on the third endite, between the basis of the setae (Fig. $4 \mathrm{f}$ and $4 \mathrm{~h}$ ). Two elements of which origin and function is unclear, with a mouse ear-like morphology, are present here (Fig. 4f and 4h). These structures cannot be seen with light microscopy. Furthermore, the first limb has a clearly pronounced gnathobasic seta on a projection (Figs. $4 \mathrm{~b}$ and $5 \mathrm{~A}$ ).

Second limb (Figs. 5E-G, 7a, 7b). Exopodite long with no seta but small setules (Fig. 5E). Endites with typically eight scrapers decreasing in size towards the gnathobase and sixth to eighth scrapers shortest (Fig. 5E). The first two scrapers are long, slender and with fine setules (Figs. 5E and 7a), second shorter than first (Fig. 5F), third scraper is markedly shorter and scrapers 3-5 gradually decreasing towards fifth scraper (Fig. 5E; fifth may be of same length as fourth; Fig. 5F). Sixth to eighth scrapers shorter by nearly half of the fifth scraper, and these three are of similar size (scraper eight a bit shorter). The first four scrapers have fine serrulation, but from scraper four to eight, serrulation is a bit thicker, and most expressed and thick in scraper six (Fig. 7a, inset). Between the third and the fourth scraper, there is a clear reduced seta (Fig. 5F, arrow and Fig. 7a, arrow). The gnathobase has a small tuft of setules, short (Figs. 5G and 7b), a sensillum (Fig. 7b) and three apical elements together on a slightly elevated basis (Figs. $5 \mathrm{G}$ and $7 b)$. Filter comb with seven setae, of which the first two are markedly shorter (Fig. 5E).

Third limb (Figs. 5H-L and 7c-g). Pre-epipodite and epipodite short and round (epipodite more or less kidneyshaped); exopodite (Fig. $5 \mathrm{H}$ ) with rectangular corm and six large marginal setae in $2+4$ arrangement; first exopodite seta about two times the length of the second; third exopodite seta about two times as long as the sixth exopodite seta, fourth and fifth setae of equal size and 

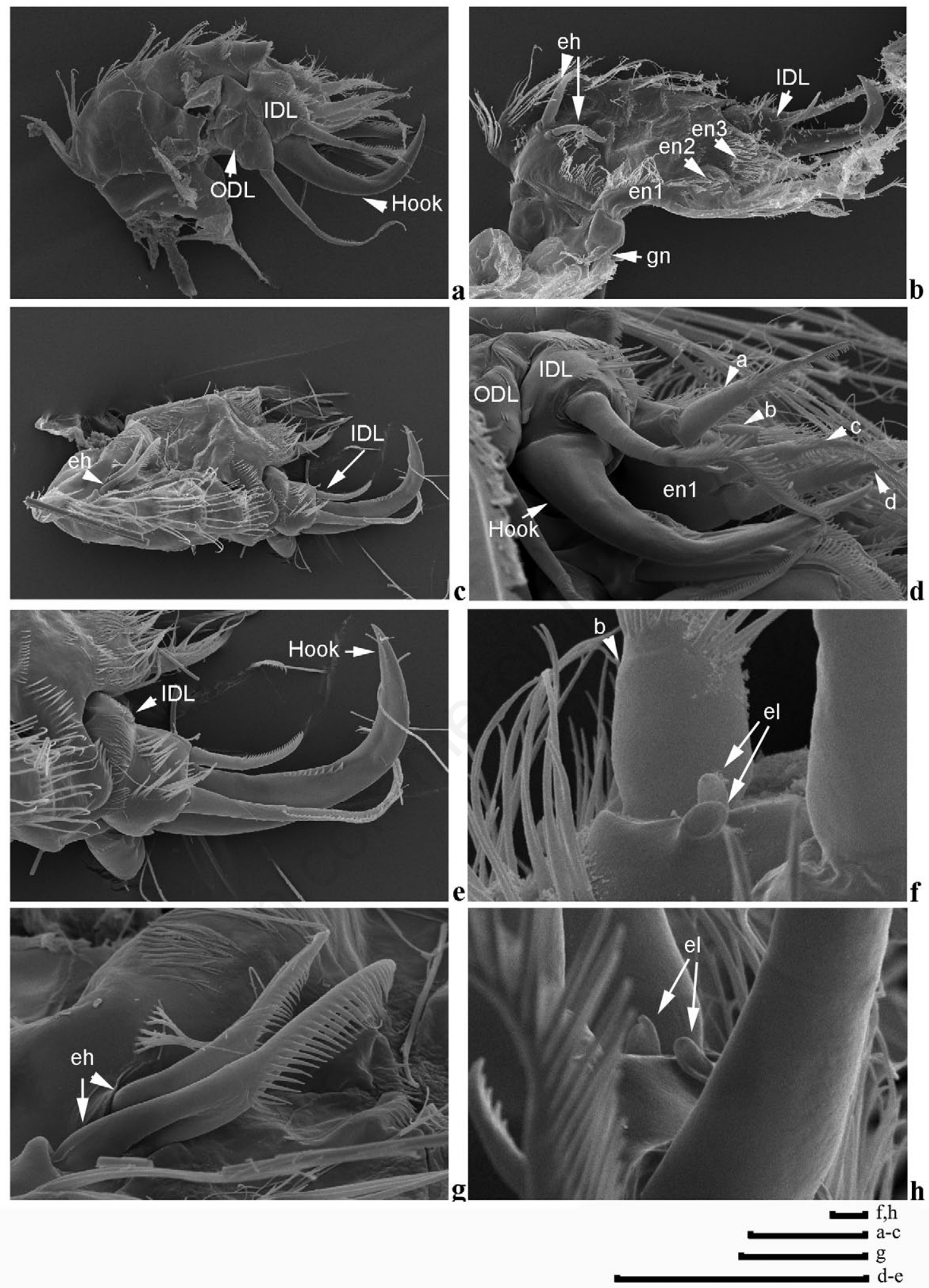

Fig. 4. Salinalona sarasinorum (Stingelin, 1900), adult parthenogenetic female from Maikhao swamp, Phuket island (Phuket province), Thailand, coll. by S. Maiphae, 27.X.2001. Scanning electron microscopy of structures on the first thoracic limb. a-c) First limb, complete; d,e) first limb, IDL with large hook; f) elements (mouse ears) on third endite; g) eh; h) elements on third endite [as in (f)]. a-h) IDL=inner distal lobe; $\mathrm{ODL}=$ outer distal lobe; gn=gnathobase; eh=ejector hooks; en1, en2, en3=endites (i.e. endopodite for second antenna) 1, 2, and 3, respectively; el=elements. Scale bars $=100 \mu \mathrm{m}$. 


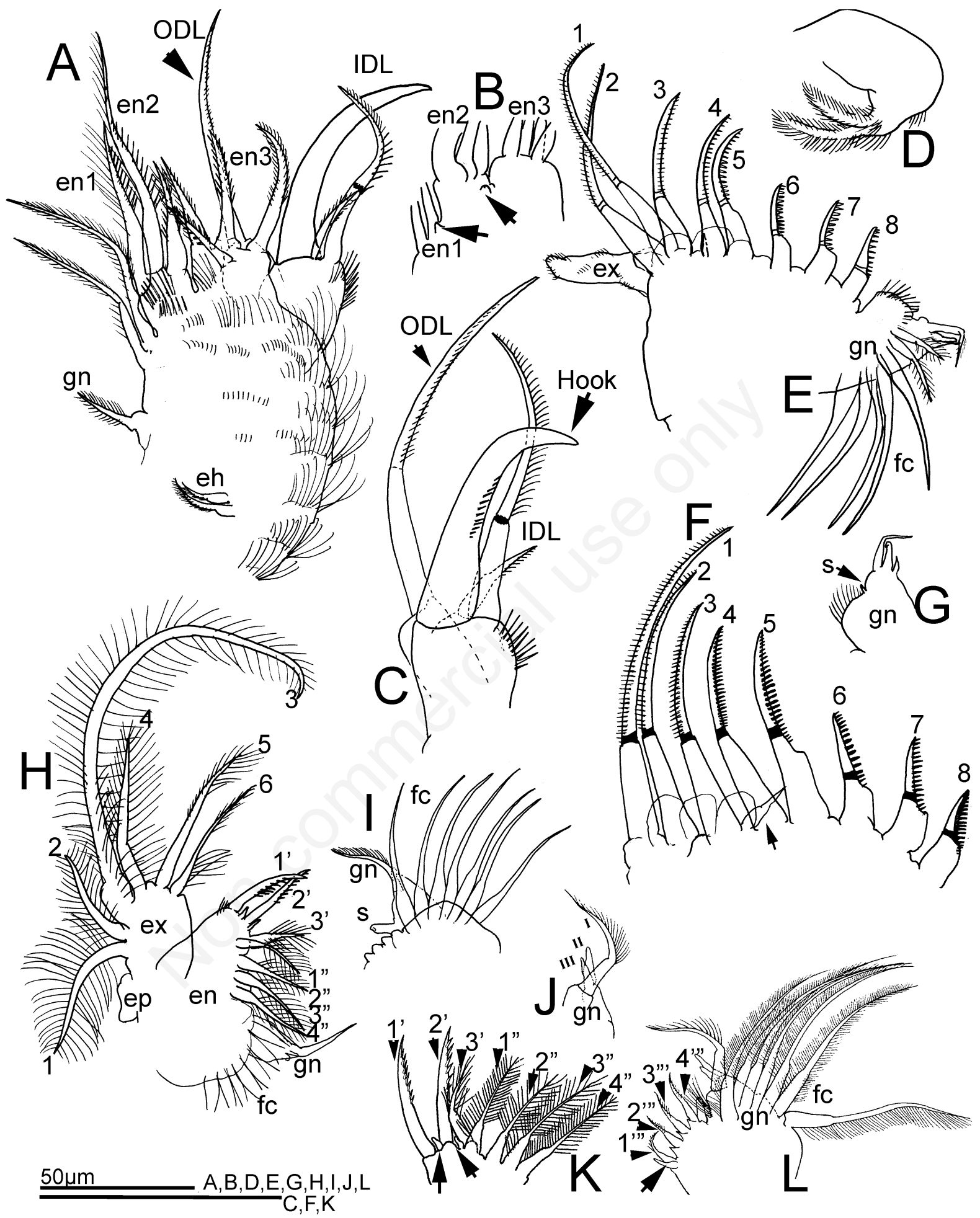

Fig. 5. Salinalona sarasinorum (Stingelin, 1900), adult parthenogenetic female from Maikhao swamp, Phuket island (Phuket province), Thailand, coll. by S. Maiphae, 27.X.2001. Limb structures (first to third limb). A) First limb; B) first limb, anterior elements; C) first limb, ODL and IDL (with hook); D) first maxilla; E) second limb; F) second limb, scrapers; G) second limb, gn; H) third limb; I,J) third limb, gn; K) third limb, proximal endite; L) third limb, internal endite and fc. A-L) eh=ejector hooks; gn=gnathobase; en1, en2, en $3=$ endites (i.e. endopodite for second antenna) 1, 2, and 3, respectively; IDL=inner distal lobe; ODL=outer distal lobe; ex=exopodite; $\mathrm{fc}=$ filter comb; $\mathrm{s}=$ sensillum; $\mathrm{ep}=$ epipodite. 
long, just longer than the sixth seta. First four setae plumose, fifth and sixth pappose in proximal half (sixth) or naked in proximal half (fifth seta) and with shorter setules (partly serrulate, partly plumose) in distal half. External endite (Figs. 5K, 7c, 7e) with three setae (1'-3' in Fig. 5K) of which first two longest and thicker, serrulate in distal half (best visible in Fig. 7e), third ( 3 ' in Figs. 5K and 7e) seta much shorter and with long setules (plumose appearance) in distal half. Between these endite setae, there are minute elements, most likely sensillae (Fig. 7f). On the inner side, four long plumose setae (1"-4" in Fig. $5 \mathrm{~K})$. On the other side, a row of four shorter setae with small setules (1"'-4"' in Fig. 7g) and one naked seta (Fig.
5L, arrow on the left). The gnathobase (Figs. 5I, 5J, 7d) has a sensillum (Fig. 5I) and, at the apex, a bent seta with two shorter blunt elements or modified setae (Figs. 5J and 7d). Gnathobasic filter comb of third limb with seven setae (Figs. 5L and 7c).

Fourth limb (Figs. 6A-E and 8a-c). Pre-epipodite round and small, epipodite very small and round as well, without fingerlike projections. Exopodite relatively round, with six marginal setae (Figs. 6A and 8a). The first two exopodite setae are similar in size (first longer than second), third seta is much longer, about 1.5 times the first two, fourth seta about half the third and same length as fifth seta, sixth seta markedly shorter (Fig. 6A). Fifth and

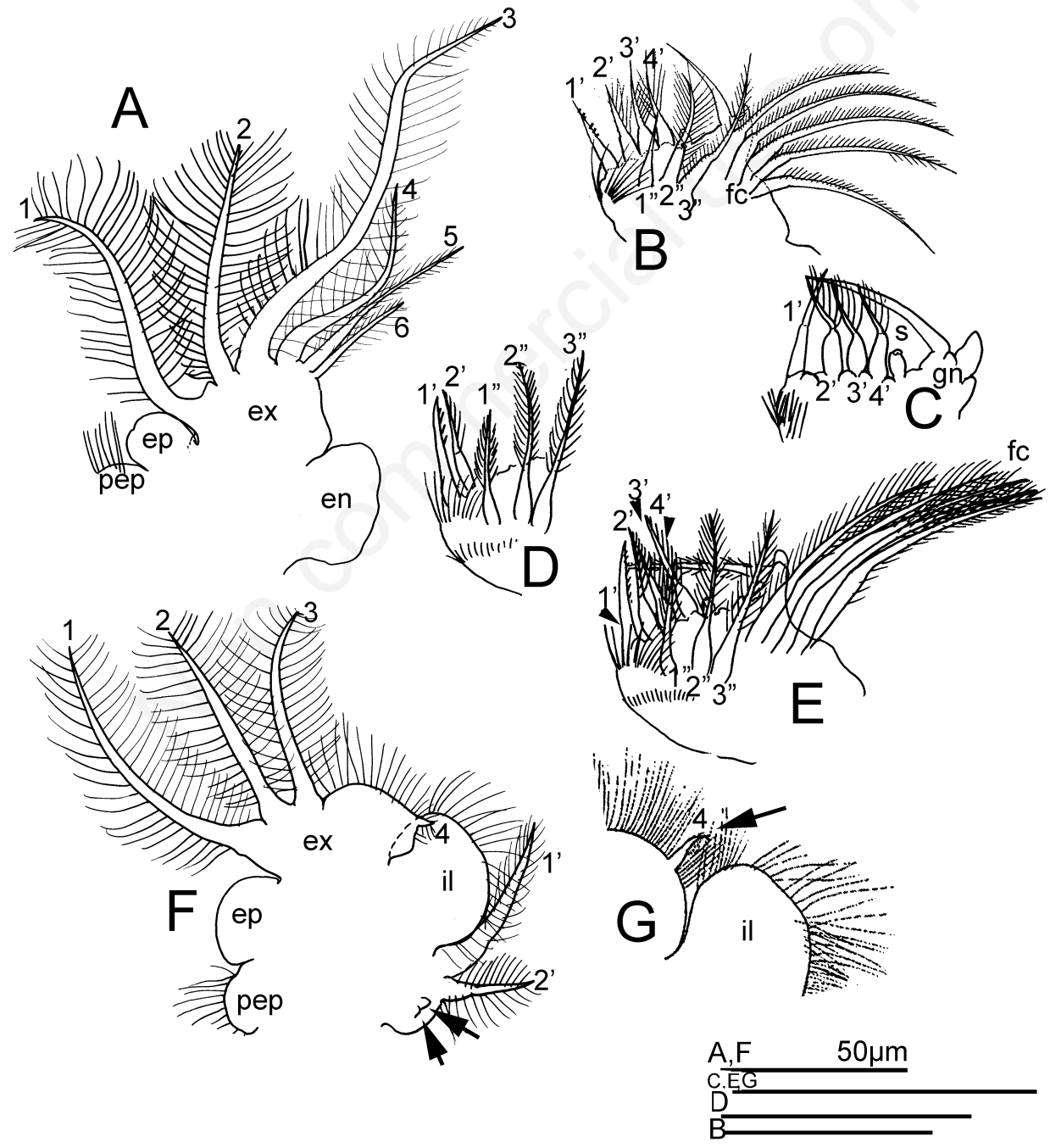

Fig. 6. Salinalona sarasinorum (Stingelin, 1900), adult parthenogenetic female from Maikhao swamp, Phuket island (Phuket province), Thailand, coll. by S. Maiphae, 27.X.2001. limb structures (fourth and fifth limb). A) fourth limb (endite not shown); B) fourth limb, endite; C) fourth limb, external endite row (flaming torch setae 2'-4') and gnathobase; D) fourth limb, internal setae (1'-3"); E) fourth limb, endite (complete); F) fifth limb (arrow points at fourth exopodite seta); G) fifth limb, distal exopodite seta (arrow) and inner lobe. A-G) pep=pre-epipodite; ep=epipodite; ex=exopodite; en=endite; fc=filter comb; gn=gnathobase; $s=$ sensillum; il=inner lobe. 
sixth setae are narrower than the other four. The endite (Figs. 6B-E and 8a-c) has a marginal row with four setae of which the first has no long setules (Figs. 6C, 6D, 8c), the other three (2'-4') have long setules on one side of the distal half (Figs. 6C-E, 8b, 8c) (2'-4' are the flaming torch setae). There is one sensillum with a wide basis (Figs. 6C and 8c) between the last flaming torch seta and the gnathobase. On the inner side, there are three well developed long plumose setae (1"-3" in Fig. 6D and 6E). The gnathobase of the fourth limb has on bent seta (Fig. 6C) and several naked projections at its basis (Fig. 6C). On the SEM, it seems to consist of two elements and one small seta (Fig. 8c). the filter comb has five well developed setae (Figs. 6E and 8b).

Fifth limb (Figs. 6F, 6G, 8d). Pre-epipodite and epipodite short and round, the latter without projections. Exopodite (Fig. 6F) shape oval, about twice as long as wide, with convex setulated margin. Four exopodite setae,
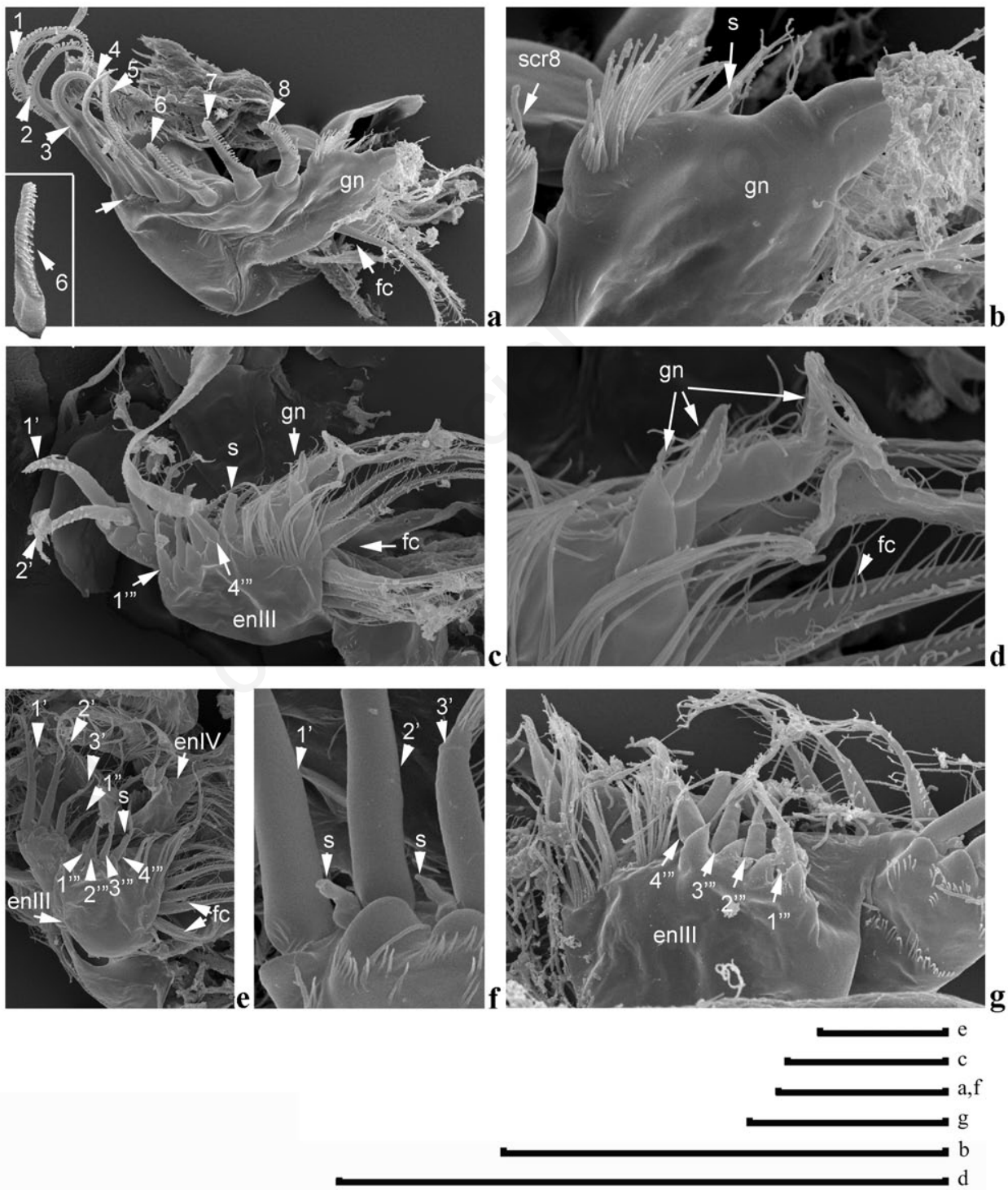

Fig. 7. Salinalona sarasinorum (Stingelin, 1900), adult parthenogenetic female from Maikhao swamp, Phuket island (Phuket province), Thailand, coll. by S. Maiphae, 27.X.2001. Scanning electron microscopy of the second and third thoracic limbs. a) Second limb, complete, with scrapers (numbered one to eight). Arrow without annotation points to small seta between third and fourth scrapers. Inset is sixth scraper enlarged; b) second limb, gnathobase; c) third limb, endite; d) third limb, gnathobasic setae on endite; e) third limb, endite, outer view; f) third limb, small elements (sensillae?) at bases of endite setae 1'-3'; g) third limb, endite, outer view. a-g) gn=gnathobase; $\mathrm{fc}=$ filter comb; $\mathrm{scr} 8=$ scraper $8 ; \mathrm{s}=$ sensillum; enIII=endite 3 ; enIV=endite 4 . Scale bars $=100 \mu \mathrm{m}$. 
of which the first three are typically long, the fourth is markedly short (Fig. 6G, arrow); inner portion of limb (Figs. 6F and 8d) with wide setulated inner lobe and two endite setae (1'-2' in Figs. $6 \mathrm{~F}$ and $8 \mathrm{~d}$ ), of which the first is just longer than the inner lobe; second endite seta (2') about half as long (Fig. 6F). Two gnathobasic elements, strongly reduced (Fig. 6G).

Sixth limb. Absent.

Ephippial female, ephippium and male: not studied here; males and ephippial females of $S$. sarasinorum remain unknown. Sediment from Maikhao peat swamp that was used in hatching experiments of rotifers in the same lab (Chittapun et al., 2005), which yielded large populations of $S$. sarasinorum (S. Maiphae, personal observation), the specimens from these independent hatching experiments were not kept and were therefore not studied in detail.
Differential diagnosis: within the genus, Salinalona sarasinorum differs from the other known species $(S$. taraporevalae), in having a postabdomen with a shallow embayment on the dorsodistal margin, short setules between the last marginal/ventral setae on the posteroventral valve corner and no clear notch on the posteroventral valve corner. Terminal spines on the second antenna well developed. The limbs can be used in case of doubt between the two: on third limb, the second exopodite seta is markedly short and the fourth exopodite seta is half as long as the third exopodite seta and on fourth limb, the third exopodite seta is twice as long as the others. See also under differential diagnosis of $S$. taraporevalae.

Distribution and biology: Salinalona sarasinorum is found in SE Asia in shallow fresh- to saline waters, marshes (also ephemeral) and estuaries. It was reported from coastal areas of Sulawesi, Indonesia (near Makassar)
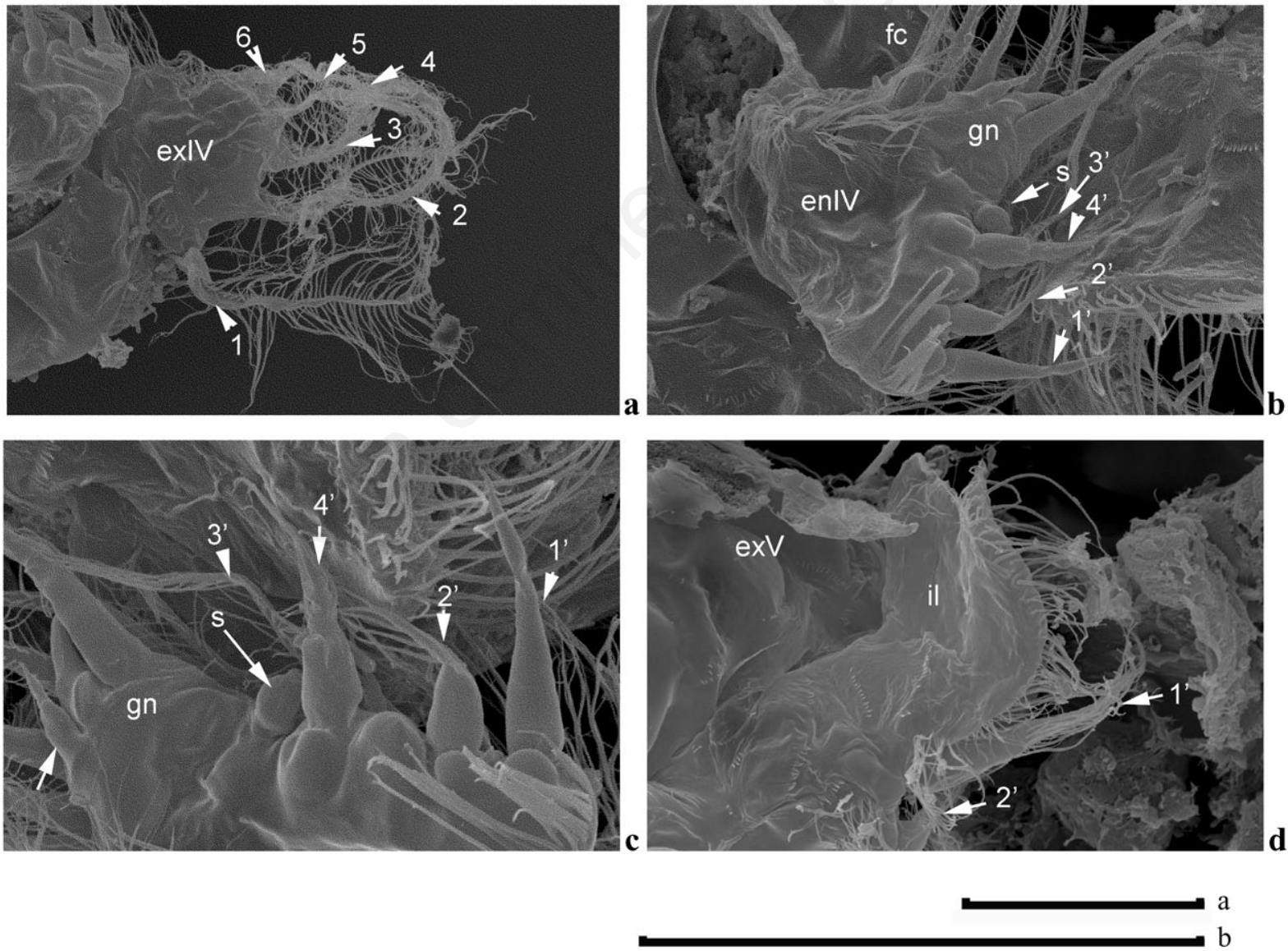

\section{b} $c-d$

Fig. 8. Salinalona sarasinorum (Stingelin, 1900), adult parthenogenetic female from Maikhao swamp, Phuket island (Phuket province), Thailand, coll. by S. Maiphae, 27.X.2001. Scanning electron microscopy of structures of the fourth and fifth thoracic limbs. a) Fourth limb, exopodite; b,c) fourth limb, endite; d) fifth limb, inner portion. a-d) exIV=exopodite 4; enIV=endite 4; fc=filter comb; gn=nathobase; $\mathrm{s}=$ sensillum; exV=exopodite 5 ; il=inner lobe. Scale bars $=50 \mu \mathrm{m}$. 
(Stingelin, 1900), from Mindanao, Southern Philippines (Brehm, 1933) and Rantang Abang marsh, the western coast in Terengganu, Malaysia (Idris and Fernando, 1981; Idris, 1983), Laos (Kotov et al., 2013), Southern Thailand (Maiphae, 2005; Maiphae et al., 2008) and SE China (new record; see below). In Southern Thailand (Maiphae, 2005) it is found in swamps and estuaries, both on coasts and on islands. It can be found mainly in summer (March-May) in waters with a $\mathrm{pH}$ ranging from 4-6 and in salinities of $0-4 \mathrm{ppt}$, yet it reaches high abundancies in high salinity sites. We found it (Maiphae, 2005) in slow-running open water in bays and estuaries in SE Thailand (Pak Panang and Pattani bay, Yaring Estuary) during rainy seasons, with $\mathrm{pH}$ 6-8 and salinities of 7-8 ppt up to $12 \mathrm{ppt}$. As for coastal swamps, we found it in Maikhao peat swamp in Phuket province (Maiphae, 2005) and a small swamp on Rawi island (present study). In Maikhao peat swamp, the species can be very abundant in areas with low water. However, this is originally mainly a freshwater site, with a significant number of Cladocera (Van Damme et al., 2013). In 1999-2000, the species was very abundant here, but less so in recent years (2011). Western coastal sites where we found $S$. sarasinorum are relatively lower in salinity (0-7 ppt) compared to the eastern sites, which are the estuaries (up to $12 \mathrm{ppt}$ ). It can be abundant in sites or periods of increased salinities (4-7 ppt). These values apply to natural conditions of the few localities where we found this animal, which are too limited for any statistical analysis and the upper boundaries of salinity tolerance in the lab have not been studied. However, no statistical analysis is needed to observe that $S$. sarasinorum can tolerate a wide range of salinities in nature. Ephippia of $S$. sarasinorum from Maikhao peat swamp were resurrected easily from dried mud by using freshwater and formed healthy and abundant populations, which we could observe during the hatching experiments of Dr. S. Chittapun at PSU (Thailand), studying rotifers from this locality (Chittapun et al., 2005).

Note on S. sarasinorum from China: On 4-7-2011, at the Workshop on Diversity and Ecology of Freshwater Zooplankton in SE Asia at the Liuxihe National Forest Park, Guangdong, China, organised by the Institute of Hydrobiology, Jinan University (Guangzhou, China), KVD could study two samples containing only S. sarasinorum, collected from two coastal swamps, one near Zhuhai City and another from Qiao island, Guangdong province, China. Unfortunately, the name of the collector and more detailed coordinates could not be found back in the notes. However, this is a new record for China, and it is most likely that this particular species has a wider distribution along the coasts and the islands of the SE Chinese province of Guangdong and could just as well be expected in the south of Guangxi province and in the coasts of Hainan island.
Salinalona taraporevalae (Shirgur et Naik, 1977) comb.nov.

Alona taraporevalae Shirgur et Naik, 1977 (Shirgur and Naik, 1977; Frey, 1991; Maiphae, 2005; Chatterjee et al., 2013; Michael and Sharma, 1988; Sharma and Michael, 1984). As A. sarasinorum in Ventakaram (1999).

Specimens examined: India - Paratypes (three specimens) of Alona taraporevalae Shirgur et Naik, 1977 mounted on a slide by D.G. Frey (Frey, 1991) from the Smithsonian Institution, USA. All the observations presented here are combined from the examination of paratypes, in turn combined with the observations and drawings in Shirgur and Naik (1977), Sharma and Michael (1984) and in particular, Frey (1991) and Maiphae (2005).

Adult parthenogenetic females: Habitus (Fig. 9A). Length 0.4-0.44 $\mathrm{mm}$. No expressed valve ornamentation. Body 1.4 times as long as high, maximum height in adults $0.27-0.32 \mathrm{~mm}$. Body shape ovoid, posterodorsal and posteroventral angles rounded, no clear posterodorsal or posteroventral corner. Posterodorsal corner quite high. Ventral carapace margin convex with deepest point near or just before middle. Marginal setae 59-78 setae (Frey, 1991). The posteroventral corner has a notch and long setules are present between the marginal carapace setae, continuing in a row parallel to the posterior valve border (Fig. 9I). Dorsum convex, maximum height of body near the middle (Fig. 9A). Carina not seen. Head. Small, frontal and high in lateral view. Rostrum round and broad (Fig. 9D), antennular corms just shorter than the rostral tip (Fig. 9A) or reaching beyond (Fig. 9D). Three connected headpores and small lateral pores.

Labrum (Fig. 9B and 9C) rather short, in lateral view with relatively straight margin and rounded ventral corner (labral keel with blunt apex). No setules observed, and there are no lateral horns. No clear indentation present on the labrum. Antennules (Fig. 9D). Short, about 1.5 times as long as wide. Sensory seta is situated at about one third from the apex and on a clear projection (Fig. 9D, arrow). No setules seen on the antennular body under light microscopy. Aesthetascs of similar size, two are slightly longer (Fig. 9D). The shorter aesthetascs, about half the length of the antennular body. Second antennae (Fig. 9H) with relatively short endopodite and exopodites (en>ex). Spinal formula 001/101, setal formula 113/003. The first endopodite seta reaches just beyond the ultimate segment of the endopod (Fig. 9H), the second endopodite seta is 1.5 times longer than the length of complete endopodite. The exopodite has a short spine on the first segment, but it is almost not seen, and the same for the terminal spines on the exo- and endopodites, which are minute. Terminal antennal setae are all fine, long and of similar thickness (Fig. 9H). 


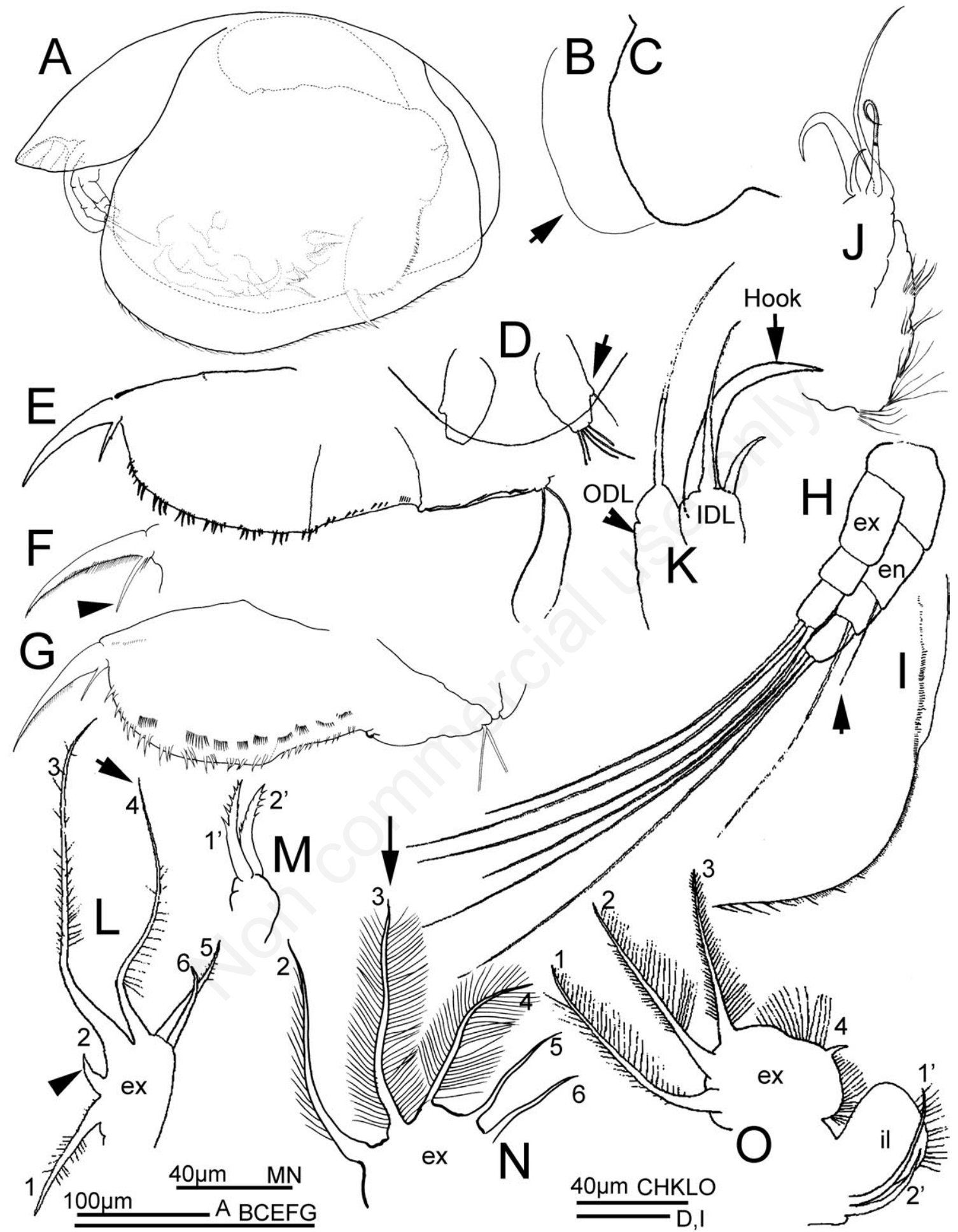

Fig. 9. Salinalona taraporevalae (Shirgur et Naik, 1977), adult parthenogenetic females, Back bay, Bombay, India, paratype series, all drawings after Frey (1991) (C-E,K,H,I,K,L,O) and Maiphae (2005) (A,B,J,F-G,M,N). A) Habitus, lateral view (degraded in type slide, eye and ocellus not visible); B,C) labral keel, lateral view (arrow at rounded tip); D) antennules and rostrum, dorsal view (arrow indicates projection on antennule); E-G) postabdomen (E,G) and terminal claw (F) (arrow indicates the long basal spine); H) second antenna (arrow indicating the short endite seta); I) posteroventral corner of valves; J) first limb, partim; K) first limb, IDL and ODL; L) third limb, exopodite (arrow pointing at second and fourth exopodite setae); M) third limb, first endite setae; N) fourth limb, exopodite (arrow indicating third exopodite seta); O) fifth limb. A-O) ex=exopodite; en=endite; ODL=outer distal lobe; IDL=inner distal lobe; il=inner lobe. 
Postabdomen (Fig. 9E-G) deepest at the postanal projection. No dorso-distal embayment near the base of the terminal claw. Length varies, about two times as long as wide (up to 2.5 times as long as wide; Ventakaram, 1999), gently tapering distally (Fig. 9E and 9G). Anal margin parallel to ventral margin. Ventral margin straight to slightly convex, longer than the anal margin, but not as long as the anal and preanal margins together. Postanal margin about twice the length of the anal margin and preanal margin about as long or longer than anal margin (Fig. 9E and 9G). The dorsodistal margin is not protruding at all. The preanal corner is weakly developed, and the postanal corner is clear but not strongly expressed (Fig. 9G). The anal margin is straight. Postabdominal armature. There are about seven to nine groups of large separate teeth on the postanal margin (Fig. 9E and 9G). These marginal teeth well-developed and arranged in clear groups of three to four each. In each group of a few spines, the distal one is slightly largest. The marginal denticles are rather curved and point in different directions (Fig. 9G). Lateral fascicles about five (up to seven) groups in the postanal region, each group similar with small spinules, not strongly differentiated in thickness, these fascicles at some distance from the postabdominal margin (Fig. $9 \mathrm{G})$. In the anal margin, the marginal denticles form a continuous row or longer groups (Fig. 9E). Terminal claw (Fig. 9E and 9F) about as long or just longer than the anal margin (less than 1.5 times as long), rather straight. Stronger proximal pecten present that reaches about half the claw (Fig. 9F) and is followed by a finer, distal pecten. The basal spine is slender and long, up to half the length of the terminal claw and at least two times, up to three times (Fig. 9F) the thickness of the terminal claw at its basis. Basal spinules are present, but relatively short, Frey (1991) notes a single longer seta on the basis of the basal spine which creates a breach in contour (Fig. 9E).

Five pairs of limbs. First limb (Fig. 9J and 9K). Epipodite not seen. Shown in Frey (1991). First endite with two long apical setae, second endite with three setae of which one distinctly longer, third endite with four setae with relatively similar thickness. Anterior elements not seen. Outer distal lobe has a slender single seta, longer than the largest IDL seta (Fig. 9K). The IDL has three setae, of which one a large hook (Fig. 9J and 9K). The two other IDL setae are shorter, the shortest about half the size of the hook and the shortest seta is also hook-like (Fig. 9K), the largest seta setulated in the distal half (Fig. 9J). Gnathobasic seta with one seta on a projection (Frey, 1991). Second limb not studied here. Frey (1991) notes that there are eight scrapers (as normal), seven setae in the gnathobasic filter comb and that three scrapers are markedly shorter than the other five and with distinct armature. Third limb with six exopodite setae (Fig. 9L) in $2+4$ arrangement of which the first is markedly longer than the second (about three times as long), the third and fourth setae are of similar lengths and both about twice as long as the fifth and sixth setae, which are of similar sizes. The latter two with very fine setulation and thinner, other four setae thicker and plumose. Endopodite with first setae (1'-2' in Fig. 9M) with strong denticles in distal halves. Gnathobasic filter plate with seven setae. Fourth limb. Exopodite with six setae (five shown in Fig. 9N), of which second and third are of the same lengths, whereas from third seta towards endopodite, the size gradually decreases. Endopodite not studied. Fifth limb (Fig. 9O). Exopodite oval-round, with four setae, of which the fourth strongly reduced in size, almost not visible. First three gradually decreasing in size. Inner lobe rounded rectangular, with two inner setae (1'-2') of which one reaches just over the inner lobe, the second much shorter, just longer than half of the first. No gnathobasic filter plate.

Sixth limb. Absent.

Males: Only described in Shirgur and Naik (1977) and commented in Frey (1991). Body length about $0.39 \mathrm{~mm}$ (Shirgur and Naik, 1977). Antennules with lateral aesthetascs and Postabdomen strongly narrowed distally and with two extensions for the gonopores (Frey, 1991: as in Leydigia, which curve dorsally on either side of the claw).

Note: In contrast to our previous suggestions (Chatterjee et al., 2013; Maiphae, 2005; Van Damme et al., 2010), we hereby suggest to keep the Indian $S$. taraporevalae (Shirgur and Naik, 1977) comb. nov. as a species. It is the first time that we revisit the latter taxon in detail and that we assess the interspecific differences. The limb differences between the paratype series shown in Frey (1991) and Maiphae (2005) with the hereby revised $S$. sarasinorum, are of species level. In particular, the setae on the exopodites of the third limb and on the fourth limb show striking differences that cannot be ignored. Even though $S$. taraporevalae should be revised at the level of $S$. sarasinorum and sexual stages of both should be compared in detail, we propose here that it is best not to lump the Indian taxon.

Differential diagnosis: S. taraporevalae is very close to $S$. sarasinorum and we regarded it as a synonym in earlier publications (Maiphae, 2005; Van Damme et al., 2010). However, our revision reveals some differences. The differences are small, but the distal margin in the postabdomen (under the base of the terminal claws) in $S$. taraporevalae has no embayment, or a very shallow one (Fig. 9E and 9G), and the preanal margin seems to be as long or shorter than the anal margin. The indentation on the labral keel is less pronounced. The posteroventral corner of the valves has a notch (not in S. sarasinorum) and between the posterior setae on the ventral margin, the small setules are relatively long, which is depicted clearly in both Frey (1991) as in Maiphae (2005), but which we did not find in S. sarasinorum. On the appendages, characters are more clear, but per- 
haps less convenient for a quick diagnosis: $S$. taraporevalae has i) a third limb with fourth exopodite seta of similar size as the third seta (Fig. 9L), which in S. sarasinorum is completely different (third seta twice as long; Fig. 5H); ii) on the same limb, the second exopodite seta is remarkably short [Fig. 9L; after Frey (1991)], less than half of the first, in $S$. sarasinorum this is as long as the first; iii) on fourth limb, the third exopodite seta is as short as the second (Fig. $9 \mathrm{~N}$ ), whereas in $S$. sarasinorum it is almost twice as long (Fig. 6A); iv) according to Frey (1991), the terminal spines on the second antenna in $S$. taraporevalae are minute, nearly not visible (Fig. 9H). In S. sarasinorum, they are relatively well developed (Fig. 2B and 2C).

Distribution and biology: $S$. taraporevalae is known from India only, reported from the vicinity of Mumbai (Shirgur and Naik, 1977) and from Tamil Nadu (Ventakaram, 1999; as A. sarasinorum). Shirgur and Naik (1977) kept this species in culture in a wide range of salinities, and suggested that it reproduces best at around 7.5 ppt (Frey, 1991). Ephippia collected at salinities of $26 \mathrm{ppt}$, were viable (Shirgur and Naik, 1977; Frey, 1991).

\section{Genus Euryalona Sars, 1901}

Euryalona cf. orientalis (Daday, 1898)

Material examined: five adult parthenogenetic females from Tabiri lake, Central Kalimantan (Borneo), Indonesia. Collected by H.J. Dumont, April 2006.

Adult parthenogenetic females: Habitus (Fig. 10A). Moderately sized chydorid, $0.56-0.62 \mathrm{~mm}$, average 0.58 $\mathrm{mm}$. In life, brownish, transparent. Ornamentation see under Carapace. Body 1.4 times as long as high, height $0.4 \mathrm{~mm}$. Body shape very round, with straight posterior margin and a clear posterodorsal corner (Fig. 10A). Dorsum straight, no real maximum height of body in lateral view (Fig. 10A). In dorsal view, body bilaterally compressed and relatively flat. Dorsal keel not seen. The posteroventral corner of the valves (Fig. 10D) is angular, with short setules which are not arranged in clusters. The body has a deep ventral point in lateral view, near the middle, and the ventral carapace margin is strongly convex (as opposed to the dorsal margin, which is straight). See more under Carapace in next paragraph.

Head. The head is frontal and high in lateral view, the rostrum oriented forward and not reaching lower than half the body height (Fig. 10A) and the headshield connecting at about one third of the total body length. Ocellus smaller than eye (eye about 1.5 times ocellus in maximum diameter), the ocellus much closer to the rostrum than the eye (distance between ocellus and rostrum is about half the distance between eye and ocellus). The rostrum is broadly blunt and round, not expressed, antennular corms just shorter than the rostral tip (Fig. 10A). Single large head pore, as for this genus, no lateral pores.

Carapace. Brownish to orange. Ornamentation exist- ing of faint lines parallel to the carapace margin (Fig. 10A and 10D), best seen in posterior portion. Marginal setae about 70-80 (Figs. 10A and 11A), in four distinct groups (Fig. 11A): one anterior group of fine, relatively long setae, oriented inwards, followed by a region with nearly no setation, a group of large setae posterior to it that are also oriented inwards, then the longest group with shorter setae that make up almost the posterior half of the ventral margin, and finally a group of much smaller setae (Fig. 11C). The carapace has a large opening in the anterior third when seen ventrally (Fig. 11A) and narrows posteriorly from there after a ventral carapace ridge (Fig. 11C). This chitineous ridge is a thickened flange which is only partly implanted with setae and that fits with the large IDL hooks on the first limb (Fig. 11C). The opening along which the ridge is formed is likely functionally related to the modified hook. In lateral view, this forms a typical indentation in the ventral carapace margin (Figs. 10A and 11B). Structure of the median carapace setae in Fig. 10C. Towards the posteroventral corner of the valves, the ventral setae become very small, end at some distance from the posteroventral corner and continue into a row of small denticles. These denticles are quite short and conical and are not arranged in groups, yet form a continuous row (Fig. 10D).

Labrum (Fig. 10B) rather short, angular. Labral keel with angular ventral corner and triangular margin in lateral view, with rows of minute setules along the labrum (Fig. 10B). The ventral tip of the labral keel is protruding, with a clear indentation; no lateral horns (Fig. 10B).

Antennules (Fig. 10E). Short, two times as long as wide. The sensory seta is situated at about one fourth from the apex, on a clear projection (Fig. 10E, arrow). No setules were seen on the antennular body under light microscopy (but perhaps they are present). Aesthetascs of two different sizes, four short, the rest longer, about as long as the antennular body. Sensory seta about same length as the longest ones. The shorter aesthetascs are about one third to half the length of the antennular body. Second antennae (Fig. 10F and 10G) with long endo- and exopodite segments, endopodite longer than exopodite by half the length of the last endopodite segment. Coxal spine not studied. Spinal formula 001/101, setal formula $113 / 003$. First endopodite seta not longer than The first endopodite seta does not reach the apical/distal margin of the second endopodite segment (Fig. 10F). The second endopodite seta reaches the end of the third segment (Fig. $10 \mathrm{~F}$ ) or is just shorter (Fig. 11G), rarely longer. The terminal endopodite and exopodite setae are all of similar lengths. The first exopodite spine is rather thick and large (on first exopodite segment) and reaches about half of the second exopodite segment. The two apical spines are short, no longer than one third (but mostly about one fourth) of the ultimate exopodite or endopodite segment 
on which they are implanted (Fig. 10G). Both ultimate spines are of similar lengths but shorter than the first exopodite spine. Terminal antennal setae are all fine, long and of similar thickness (Fig. 10A).

Postabdomen (Fig. 10H) very long, and deepest at the preanal projection. Very deep dorso-distal embayment near the base of the terminal claw. Length varies, but about 4.5 to 5 times as long as wide, tapering distally and with clearly concave postanal margin. Ventral margin straight to convex in distal half, much longer than the anal and preanal margins together. Postanal margin about three times as long as anal margin, preanal and anal mar-

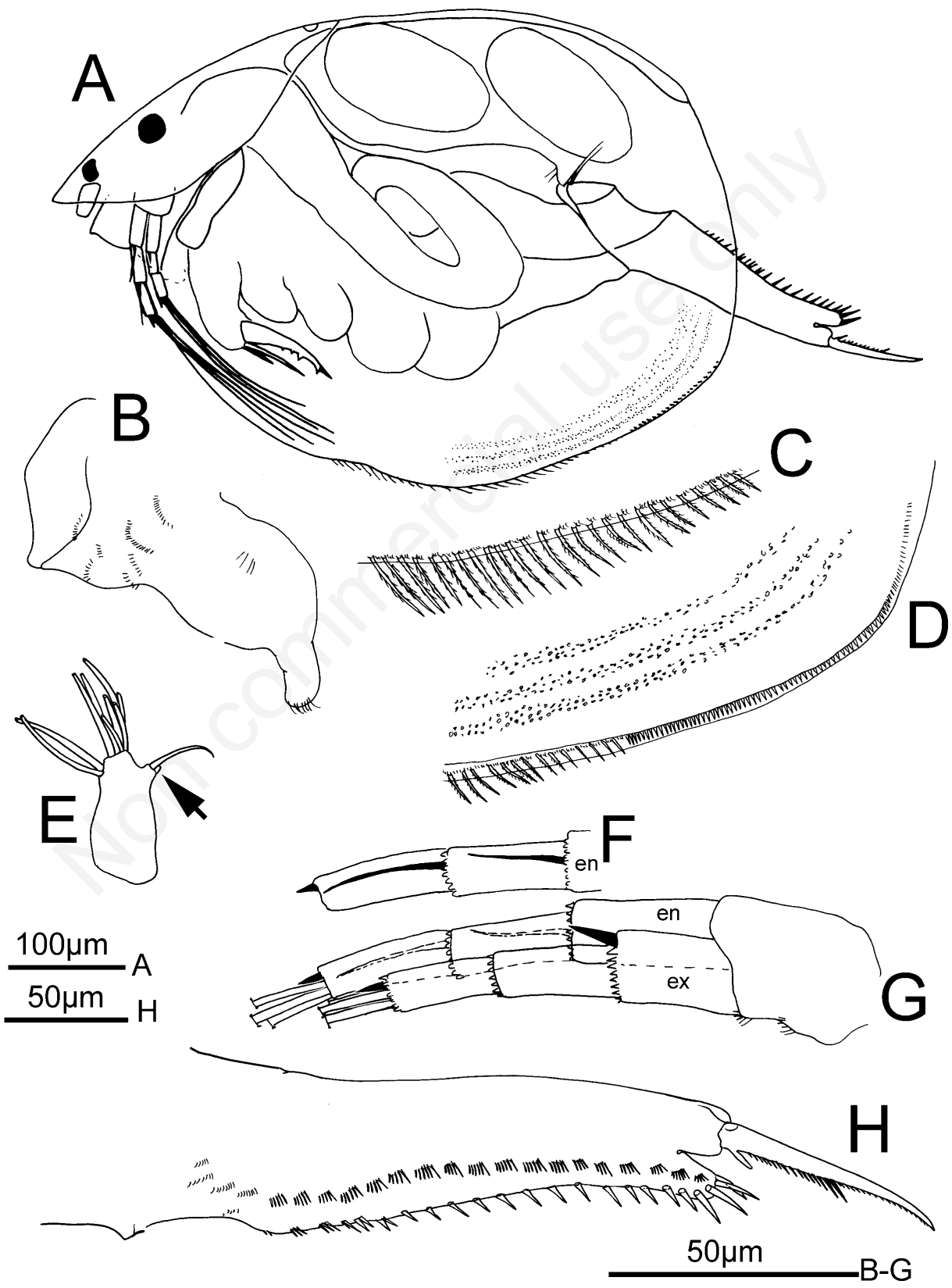

Fig. 10. Euryalona orientalis (Daday, 1898), adult parthenogenetic female from Tabiri lake, Central Kalimantan (Borneo), Indonesia, coll. by H.J. Dumont, April 2006. A) Habitus, lateral view; B) labrum, lateral view; C) carapace, ventral setae; D) carapace, posteroventral corner; E) first antenna (arrow on projection); F) second antenna, endopodite; G) second antenna (apical setae truncated); H) postabdomen. A-H) en=endopodite; ex=exopodite. 
gin of similar lengths (preanal just a bit shorter). Dorsodistal margin is strongly protruding, reaching beyond the terminal claw base, and the terminal claws themselves are on a projection of the end of the carapace. Preanal corner well expressed and deep, postanal corner not developed, just a weak rounded bend. Anal margin concave. Postabdominal armature. There are about 22-25 large separate teeth on the postanal margin (Fig. 10H), which are single and only form a few (about five) groups near the anal margin (each group about two to three denticles). The marginal teeth are long and strong, and form a continuous row, which increase in size distally, the largest spines protruding forward on the dorsodistal projection (just under the base of the basal claw in Fig. 10H). There are about 18-20 lateral fascicle groups on the postanal margin, with very short spinules that end at some distance from the postabdominal margin. In the anal margin, they continue in lateral fascicles in three to more rows. Each fascicle in postanal portion has about four to six spinules, these spinules are not differentiated in thickness (Fig. 10H). Terminal claw (Fig. 10H). About two times as long as the anal margin and very straight (only the tip is curved). The terminal claw is on a projection, separated by the deep embayment (about two times claw width at basis). The basal spine is short, no longer than the terminal claw thickness at basis, and the proximal pecten is well developed, with the distal spinule(s) in it, strongly developed and protruding forward. Distal pecten, which starts just over half of the claw's length, is much shorter. Basal spinules very small.

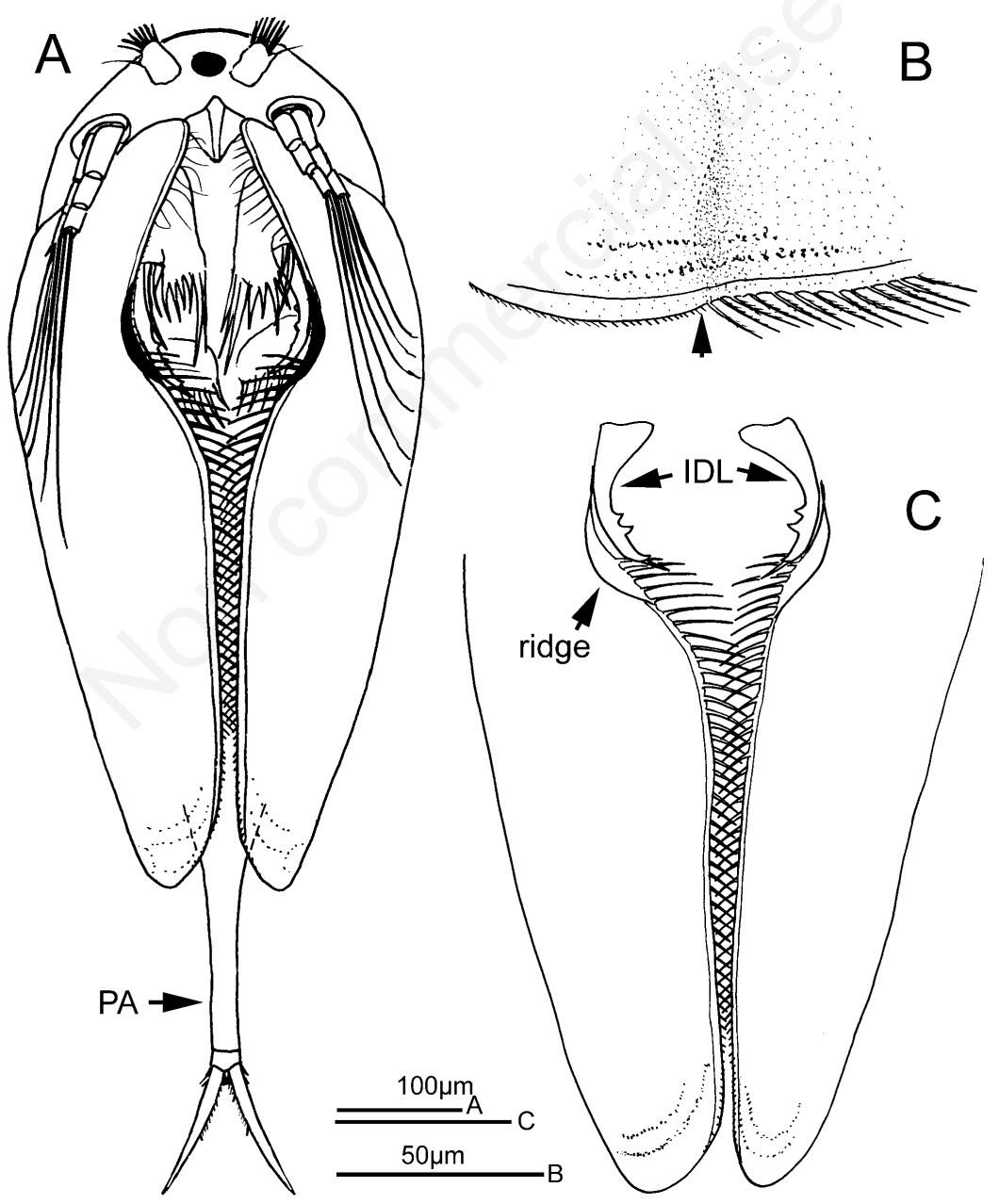

Fig. 11. Euryalona orientalis (Daday, 1898), adult parthenogenetic female from Tabiri lake, Central Kalimantan (Borneo), Indonesia. coll. by H.J. Dumont, April 2006. A) Habitus, ventral view; B) carapace embayment (arrow indicates the indentation in the carapace, viewed laterally); C) detail ventral view of carapace margin with setae, showing IDL hook and thickening (ridge). A-C) PA=postabdomen; IDL=inner distal lobe. 
First maxilla with two bent large plump setae with fine setules (Fig. 12F). Five pairs of limbs (Figs. 12 and 13).

First limb (Fig. 12A-E). Epipodite short and round (Fig. 12A). First endite with two long apical setae (Fig. 12A) and a large anterior seta (Fig. 12B, black seta on left; and Fig. 12C, arrow left), second endite with three setae, of which two distinctly longer and one large anterior seta which is larger than the seta on first endite (Fig. 12A, seta in black on the right; Fig. $12 \mathrm{C}$, right arrow). Third endite with four setae of similar size (Fig. 12A), one is unilaterally setulated (Fig. 12B). Inner distal lobe with strongly modified hook and two adjoining smaller setae, ODL with normal long slender seta with small setules in distal half to two thirds (Fig. 12D). The large IDL hook has two large teeth on it, which are not implanted but outgrowths of the structure. The apex of the hook is setulated to one side (Fig. 12D, black part). The hook's base is as thick as one third of its length. The other two IDL setae are smaller, but also stout and rather thick, the largest one has a strong denticulation in the distal half, the smallest one is just unilaterally armed with short setules in distal half. The ODL seta is longer than the IDL hook. In the complete animal, this IDL hook is moveable and supported by a chitineous ridge of the carapace, the latter bent exactly to parallel the curve of the hook (Fig. 11C). Six to seven groups of setules on the anterior limb margin (Fig. 12A). Ejector hooks large, one clearly larger than the other (Fig. 12A, eh). Gnathobase is represented by single, large and well developed seta, on a small projection (Fig. 12E).

Second limb (Fig. 12G and 12H). Exopodite elongate, with terminal tuft of thick setules (Fig. 12G, ex). Endites with eight scrapers generally decreasing in size towards the gnathobase (Fig. 12G). First three slender and long, gradually decreasing in size, followed by markedly shorter fourth scraper (shorter than fifth), fifth relatively fine and longer than fourth and sixth, the latter also markedly shorter (shorter than seventh), eighth shortest; fourth, sixth and seventh scrapers are thicker than the others but for the rest, serrulation is rather similar (none with extremely thick denticles), differentiation is in the thickness of the scrapers rather than the armature (Fig. 12G). On the endite scales, behind fourth and fifth scrapers, a small projection on the distal scale. Gnathobase with group of setules, relatively elongate tuft, followed by a long sensillum (Fig. 12G, indicated as $s$, and Fig. 12H). The three apical setae on the gnathobase are together on an elevated basis (Fig. 12H), first a longer seta, second a shorter, bottle-like seta with blunt apex, third a plump seta with rounded apex as well (smaller than the second). Filter comb with seven setae, of which the first is markedly shorter than the second (about half as long) (Fig. 12G, labeled as fc).

Third limb (Fig. 12I-L). Pre-epipodite not studied. Epipodite oval and without projections (Fig. 12I). Seven exopodite setae (Fig. 12I) on a long rectangular exopodite body, with first strongly developed and thicker than second but of similar length, third longest (just over twice length of the second), fourth and fifth short and thick, fifth about half the length of the fourth seta; setae six and seven narrow, sixth longer than seventh. The fourth seta is about the same length of the sixth, the seventh is longer than the fifth. All the setae are plumose except sixth and seventh, which are armed in first half with short setules (Fig. 12I). External endite with two setae (1'-2' in Fig. 12J), which are both slender and the first is shorter than the second by nearly half. On inner side, four setae that are well developed, long and plumose (1"-4" in Fig. 12K). On the other side, four long plumose setae (1" to 4 "' in Fig. 12L) and one small naked seta near the base of the first (arrow in Fig. 12L). The gnathobase consists of a sensillum ( $\mathrm{s}$ in Fig. 12L) and a large bent gnathobase seta with two basal naked setae (Fig. 12L). The filter plate of the third limb consists of seven long setae (Fig. 12L).

Fourth limb (Fig. 13A-D). Pre-epipodite rather quadrangular and elongate, epipodite round to oval with long projection that is bent and long (about two times the length of epipodite itself). Exopodite very round, with setae in a $2+4$ arrangement, with rows of small denticles on the corm. First two exopodite setae long and slender, second slightly smaller than first, between second and third exopodite setae there is a convex margin with tufts of setules (not a continuous row). The third exopodite seta is long, more than twice the size of the second and twice the size of the fourth (Fig. 13A). Fifth and sixth setae finer than the other exopodite setae (Fig. 13A), the fifth about 1.5 times longer than the sixth (the sixth is half the size of the fourth). The first two exopodite setae are widely plumose, setae three and four have short setulation/serrulation only in the distal halves. The endite (Fig. 13B-D) has four setae on its margin, of which the first is markedly short (1'), the other three (2'-4') longer (2' just a bit longer than 1', but 3' and 4' twice as long). These setae, do not look like flaming torch setae at all (2'-4'), but are long, slender and have very short setulation in distal halves. At the basis of setae 3' and 4', there is a minute element (Fig. $13 \mathrm{C}$, arrow). The sensillum between the last seta of this row and the gnathobase ( $s$ in Fig. 13B) is elongate. On the inner side of the endite, there are three (1"-3") long and well-developed plumose setae (Fig. 13D). The filter plate of the fourth limb exists of five setae (Fig. 13D).

Fifth limb (Fig. 13E). Pre-epipodite rectangular, about 1.5 to 2 times as long as wide, and epipodite oval kidneylike, with a long finger-like projection that reaches the centre of the fifth exopodite. Exopodite shape broadly round, about twice as wide as its high, with rows of small denticles on the corm, and with large convex setulated margin (between setae three and four). Four exopodite setae, of which the first two are long, the third is markedly 


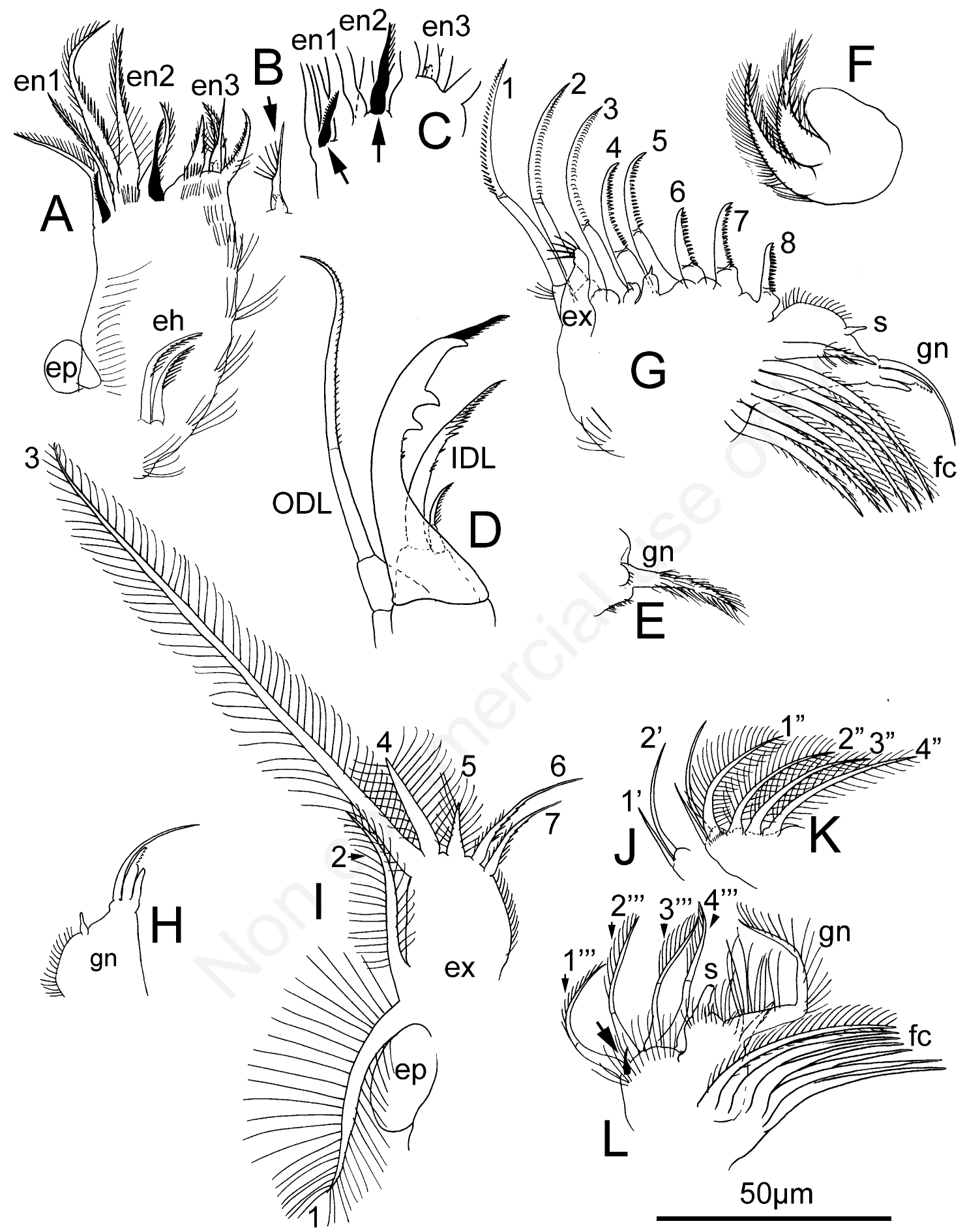

Fig. 12. Euryalona orientalis (Daday, 1898), adult parthenogenetic female from Tabiri lake, Central Kalimantan (Borneo), Indonesia, coll. by H.J. Dumont, April 2006. A) First limb (ODL and IDL not shown); B) first limb, seta on third endite; C) first limb, anterior view of corm apex with anterior setae (arrows); D) first limb, ODL and IDL; E) first limb, gnathobase; F) first maxilla; G) second limb; H) second limb, gnathobase; I) third limb, exopodite and epipodite; J) third limb, endite setae 1'-2'; K) third limb, inner endite setae (1"-4"); L) third limb, endite setae 1'"-4"' and gnathobase, with gnathobasic filter comb. A-L) ep=epipodite; eh=ejector hooks; en1, en2, en $3=$ endites (i.e. endopodite for second antenna) 1, 2, and 3, respectively; ODL=outer distal lobe; IDL=inner distal lobe; $\mathrm{gn}=$ gnathobase; ex=exopodite; $\mathrm{s}=$ sensillum; fc=filter comb. 
shorter, about half of the second, these three all of similar thickness. The fourth is longer than the third, yet still shorter than the second and first exopodite setae, and it is narrower by half of the preceding setae. Inner portion of limb with wide inner lobe that is broadly diamond- to pear-shaped and with a tuft of strong thick setules on its apex. Two endite setae (1'-2') of which one reaches one third of its length over the inner lobe apex; second endite seta (2') just longer than half of the first. Two gnathobasic elements, strongly reduced (Fig. 13F).

Sixth limb. Absent.

Ephippial female, ephippium and male: Not studied here [Rajapaksa and Fernando (1987) for E. orientalis].

\section{DISCUSSION}

\section{Morphological peculiarities}

One of the most striking features of Salinalona gen. nov., if not the most striking feature, is the large modified hook-like seta on the first limb. Besides being a typical (parallel) adaptation in male Chydoridae for grasping females during copulation (male claspers) (Smirnov, 1971; Van Damme and Dumont, 2006), it is unusual for females to have a large modified hook on the first limb, especially in the Aloninae (Fig. 14). In this respect, Salinalona gen.nov. shows a similarity with Euryalona Sars, 1901, as Frey (1991) mentioned. Some Aloninae have a thickened hook-like seta on the first limb, like in Alona affinis (Leydig, 1860), or some species of Camptocercus Baird, 1843, Coronatella Dybowski et Grochowski, 1984, Anthalona Van Damme, Sinev et Dumont, 2011 and to a lesser extent, Kurzia Dybowski et Grochowski, 1984 (Smirnov, 1971, 1998; Van Damme and Dumont, 2008a; Van Damme et al., 2011), yet it might be not homologous to the hook-like seta in Salinalona, and this character is otherwise relatively unusual within the subfamily. The variety of these IDL structures in the subfamily is relatively wide (Smirnov, 1971) and may serve different functions. In the Chydorinae, a relatively strong hook on the IDL of the first limb of females is more common, as in many Chydorus Leach, 1816 (e.g. the C. sphaericus-group) and in Disparalona Fryer, 1968, Alonella Sars, 1862, Pleuroxus Baird, 1843 and Peracantha Baird, 1843 (Fryer, 1968; Frey, 1993a; Smirnov, 1971, 1999). A hook-like seta on the first limb also occurs in other anomopod families, such as in the Macrothricidae (Bunops Birge, 1893) (Silva-Briano and Dumont, 2001) and the Eurycercidae (Eurycercus Baird, 1843) (Smirnov, 1971). One of the main functions of this clasping hook-like structure is to grasp, scrape and tear filamentous algae or other (plant or detrital) material during grazing or for creeping, crawling and attachment to the substrate (Fryer, 1968; Smirnov, 1971, 1999). Nowhere in the known Chydorinae is this hook as specialised and as modified as it is in the genera
Anchistropus Sars, 1862 and Pseudochydorus Fryer, 1968 (Fig. 14). The function of the modification in these two genera is related to feeding habits: these animals are considered as the only truly carnivorous Chydoridae and the hooks function to tear out parts of their prey, Anchistropus as an active predator and Pseudochydorus as a scavenger (Fryer, 1968; Van Damme and Dumont, 2007). The origin of the hook is completely different in both: in Anchistropus it is part of the ODL, whereas in Pseudochydorus it derives from an IDL seta (Van Damme and Dumont, 2007). The feeding habits have resulted in the convergence of a first limb seta into a similar structure with similar function (Van Damme and Dumont, 2007).

Are the hooks in Salinalona and Euryalona a result of convergence because of similar feeding habits, with the same function as those in the carnivorous Anchistropus and Pseudochydorus? Or are they used for attachment to the substrate and for crawling, instead of for food collecting? The modification is quite extensive in comparison to other Aloninae females and more numerously found to such extent in Chydorinae. It could be possible that the modified IDL seta in Euryalona and Salinalona is homologous to the seta in Pseudochydorus and perhaps it could serve a similar function. Similarly, it could be possible that Euryalona and Salinalona are carnivorous, either active predators or scavengers. If not carnivorous, then we can expect the habits of these genera to be related to a need for strong attachment to substrate or to crawling, as the specialisation is too extensive to accompany exactly the same needs in nature as species with a normal first limb. In Euryalona, we observed that the carapace is especially strengthened, widened and modified for these extensive hooks, with a well-fit ventral carapace gap and adjoining sclerotised ridges (Fig. 11), convergent with $A n$ chistropus where the carapace is modified to accompany the hooks (Van Damme and Dumont, 2007). It is clear that a certain amount of force is required for grasping whatever it is that these chydorids hang on to or handle. Fryer (1968) suggested that the development of such thicker parts of the carapace contribute to the adherence to substrate (Smirnov, 1971). Frey (1991) noted that in S. taraporevalae, the first limb setae of the other endites seem to be relatively small, so that it seems that the whole limb is modified to accomodate the hook-like structure. The question of what the feeding habits of Euryalona and Salinalona are, remains unanswered. The answer would require live observations of foraging, combined with gut content analysis. As Frey (1991) noted on S. taraporevalae: An understanding of the habits of the taxon in relation to the use of the hook on trunklimb I would be significant and highly informative. In any case, the modifications are undoubtedly related to the exploitation of a particular feeding niche. The fact that Shirgur and Naik (1977) were able to culture $S$. taraporevalae on algae, does not exclude that the animals handle other food 


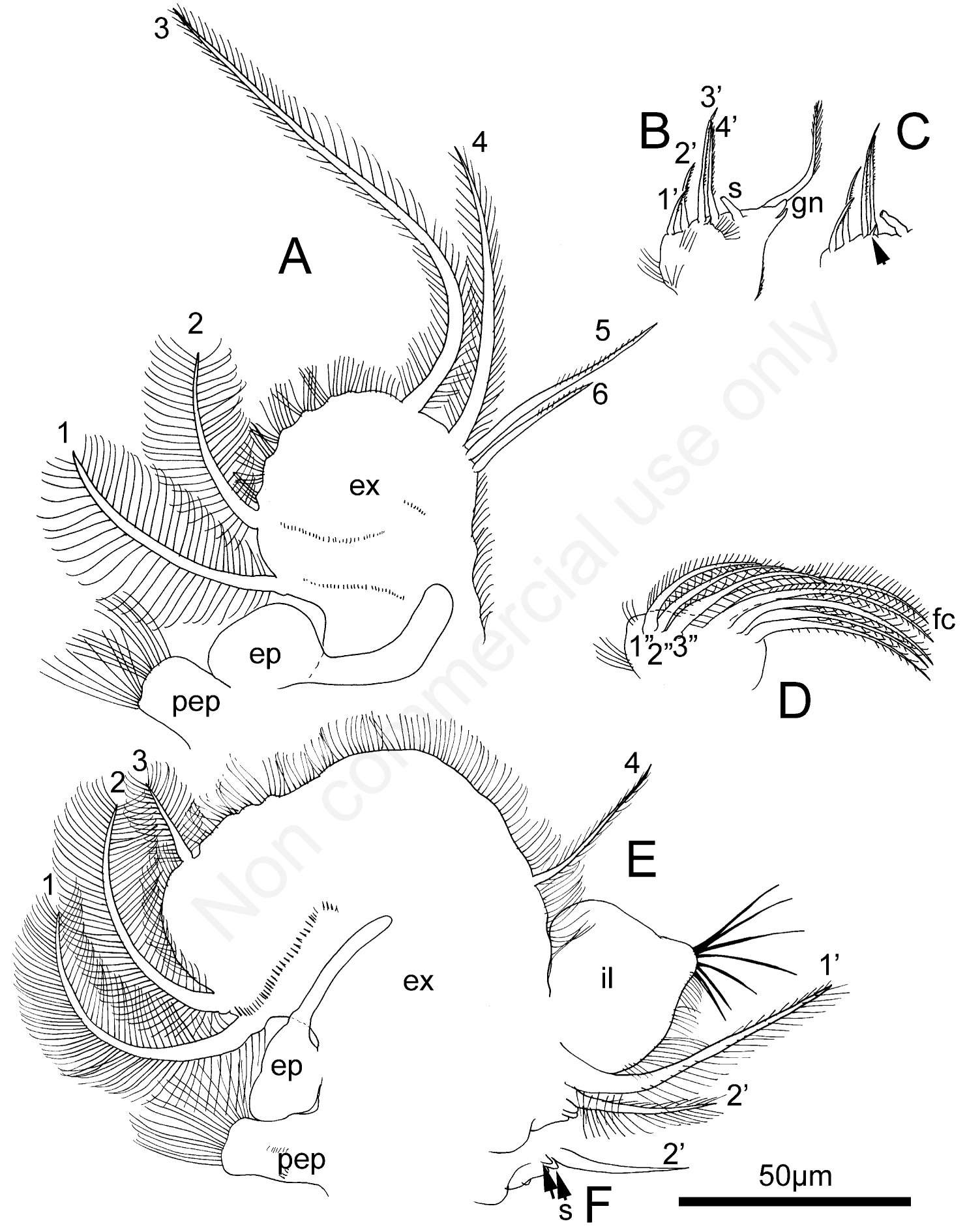

Fig. 13. Euryalona orientalis (Daday, 1898), adult parthenogenetic female from Tabiri lake, Central Kalimantan (Borneo), Indonesia, coll. by H.J. Dumont, April 2006. A) fourth limb (endite not shown); B) fourth limb, endite, with modified flaming torch setae (2'-4') and gnathobase; C) idem (arrow at small element); D) fourth limb, endite with inner setae (1"-3") and gnathobasic filter comb; E) fifth limb, complete; F) detail of fifth limb with gnathobasic elements (s) and setules omitted from the second inner seta (2'). A-F) pep=preepipodite; ep=epipodite; ex=exopodite; $\mathrm{s}=$ sensillum; gn=gnathobase; fc=filter comb; $\mathrm{il}=$ inner lobe. 
sources in their natural environment. It does suggest that Salinalona is not overspecialised. As most cladocerans, these animals would be able to switch between different types of food for a time, as long as it is palatable, processable, and abundant. There is no data on culturing or feeding of Euryalona. Sars (1901) is the only author that published live observations on the genus and he wrote that in free water Euryalona can swim rather rapidly, with large leaps and that this is predominantly a bottomdweller. However, there are more similarities between $\mathrm{Eu}$ ryalona and Salinalona gen. nov. than the first limb hook, which is likely the result of convergence.

\section{Proposing Salinalona as a new genus}

Besides being superficially similar in external features such as the habitus, headpores and postabdomen, Salinalona gen. nov. is not closely related to Alona. In habitus, these animals indeed look like general Alona species, yet the convergent body shape has been the main reason for lumping many taxa (Van Damme and Dumont, 2008a, 2008b; Van Damme et al., 2010). The three main connected head pores with small lateral pores and the general body- and postabdomen shape, would traditionally have been important characters for keeping sarasinorum and taraporevalae in Alona. However, the use of head pores as a major character in Alona has been given a different phylogenetic weight over the past few years than before (Van Damme and Dumont, 2008b). If we consider the central core of Alona as A. quadrangularis and Alona members of the Hexalona clade (e.g. affinis-, guttata-, in- termedia-, costata-, rustica-groups), most of which have six pairs of limb (Van Damme and Dumont, 2008a, 2008b), the new genus differs in more than one relevant character state: i) five limb pairs, not six (even though $A$. quadrangularis also has five); ii) unmerged marginal denticles on the postabdomen; iii) first limb with no accessory seta (below the ODL); iv) no exopodite seta on second limb; v) six setae on the exopodite of the third limb; vi) fifth limb with a convex margin and a gnathobase without a filter comb. Subtle as these characters might seem, they are significant in a basic split in Alona (and in fact, in the Aloninae) (Van Damme and Dumont, 2008a). Several of these character states are reductions that lean closer to the Coronatella-branch, which also has six setae on the exopodite of the third limb and unmerged marginal denticles on the postabdomen. However, Salinalona does not fit in the genus Coronatella or any of its associated genera, which are characterised by strong reductions on the limbs. Leberis and Celsinotum, to which Frey (1991) compared taraporevalae, are much closer to Coronatella than to Alona (Van Damme and Dumont, 2008a) and Salinalona can not be grouped under any of the existing five-limbed Aloninae genera of the Coronatella-branch, nor any other genus in the Aloninae with five limbs. This includes the recently described Extremalona, an euryhaline species which belongs to the Coronatella-branch as well (Sinev and Shiel, 2012). It is possible that the limb reductions (e.g. absence of sixth limb and fifth limb gnathobase, the absence of a seta on the third limb's exopodite) in Salinalona happened independently from the Coronatella

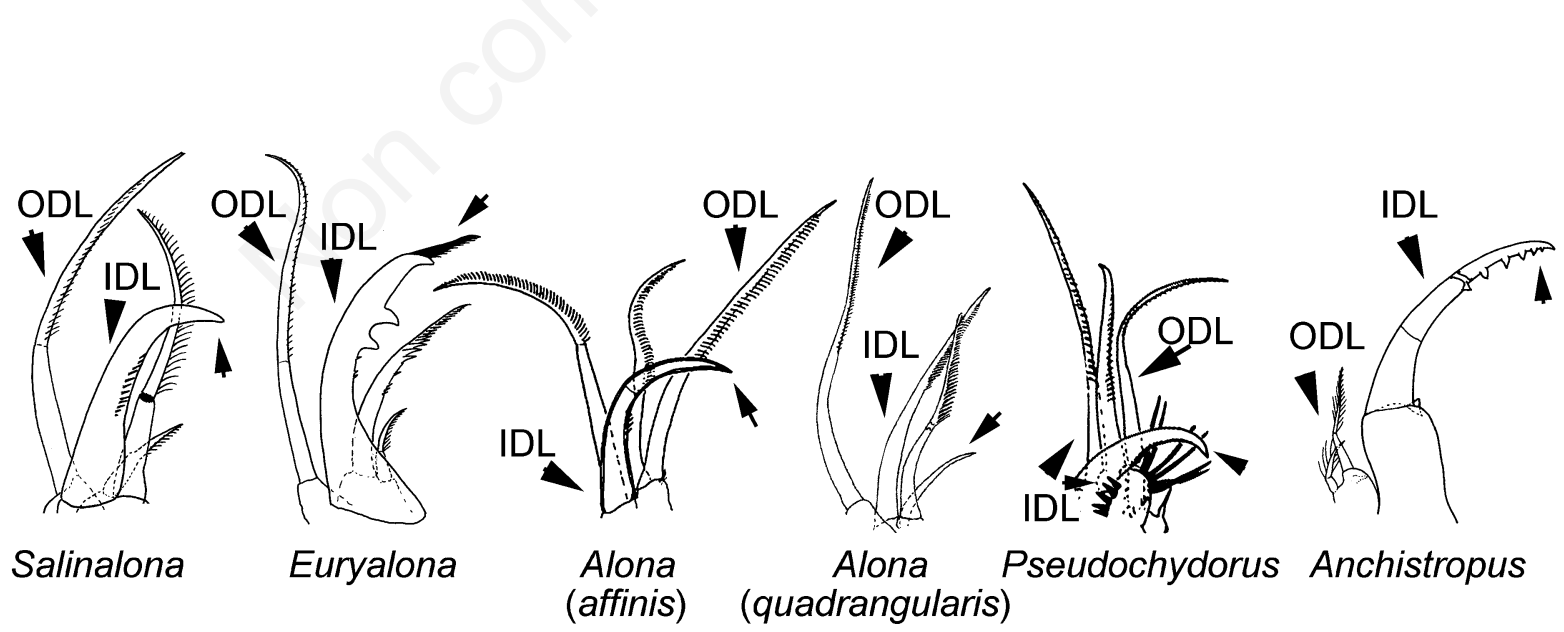

Fig. 14. The ODL and IDL setae of the adult female first limbs in Salinalona gen. nov. compared to the Aloninae Euryalona, Alona affinis (after Van Damme and Eggermont, 2011), Alona quadrangularis (O. F. Müller, 1776) (after Van Damme and Dumont, 2008b), and the peculiar Chydorinae Pseudochydorus and Anchistropus [after Van Damme and Dumont (2007)]. The modified seta is not homologous between all taxa, and it is shown here mainly to illustrate the extent of the modification in Euryalona and Salinalona in comparison to a few selected taxa. The hooks in Salinalona and Euryalona are strongly developed, more than most other Aloninae, like in A. quadrangularis, even in comparison with species with a hook-like seta, even though not homologous (e.g. Alona affinis). In the Chydorinae, hook-like setae on the IDL are more common, but modified into special structures in Pseudochydorus and Anchistropus. In the latter, the hook is part of the ODL, not the IDL. The function of these hook-like setae in Euryalona and Salinalona remains unknown. $\mathrm{ODL}=$ outer distal lobe; IDL=inner distal lobe. 
branch and that this small lineage derived from a basal split in the subfamily. For example, the endites of the third and fourth limbs, show primitive states, different from Coronatella and related genera. The flaming torch setae of the endite of the fourth limb and its inner setae (2'-4' and 1"-3" in Figs. 6 and 8), as well as the endite setae of the third limb (1"-4" and 1" -4 "" in Figs. 5 and 7), are all well developed and do not show the strong modifications that are more typical for Alona, Coronatella and closest related taxa. Furthermore, on the first limb, there are three setae on the IDL, whereas in the Coronatella-branch, the IDL has only two setae (one is strongly reduced). Besides the former characters, which to us are valid arguments that Salinalona is definitely not an Alona, Coronatella, or any of their closely related genera, the new genus has a number of peculiar characters that form a further argumentation for its separation.

As Shirgur and Naik (1977) and Frey (1991) stated on taraporevalae, there are several aspects which make Salinalona hard to place within the Aloninae. The most important are: i) the large hook on the IDL of the first limb, which is likely the result of strong specialisation (see above); ii) full sets of setae on the endites of third and fourth limbs; iii) strong reduction of an exopodite seta (the fourth seta) on the fifth limb; iv) a strong projection on the first antenna, on which the sensory seta is implanted; and $v$ ) the spiniform setae on the ventral valve margin (which are mainly implanted submarginally, not marginally). Even though we did not study males in detail, Frey (1991) correctly remarks on the first antenna of males taraporevalae that it has lateral aesthetascs and on the elongate, narrow Chydorinae-like postabdomen with projections for the sperm ducts, depicted in Shirgur and Naik (1977). Frey (1991) remarks that the male postabdomen is in fact unique within the Aloninae. On themselves, the latter two characters would already be strong arguments for a generic status. On top of that, there are the peculiar characters listed above and the fact that Salinalona species cannot be fit in any other existing genus of the Aloninae.

The projection on the female first antenna is a character that is quite remarkable and its phylogenetic importance might have been under-appreciated until now. In Chydorinae, this can be more common, but in Aloninae, it is highly unusual and has not received attention. In combination with the fact that males of $S$. taraporevalae have a Chydorinae-like postabdomen, this character draws our attention. The projection does occur in the Aloninae genera Notoalona Rajapaksa et Fernando, 1987 and Euryalona Sars, 1901 for example, the latter depicted in this study [for Notoalona see Van Damme et al. (2013)]. Therefore, we suppose that there is more to the similarities between Euryalona and Salinalona besides the hook, which is likely a homoplasy. Both genera are so different in their basic morphology (postabdomen, habitus, headpores) that a phylogenetic link would seem far-fetched and these two genera likely have separated early in chydorid evolution. However, we think the antennular projection should not be ignored. There are more similarities, like the fact that both Euryalona and Salinalona have three well developed IDL setae on the first limb and lack the extra (accessory) seta near the basis of the ODL which is present in most Aloninae, or that both genera lack the seta on the exopodite of the second limb, and have well developed endite setae on the third limb. The labral keel also shows similarities (with the indentation, and small lateral setules) and the flaming torch setae on the fourth limb are quite long and not typically compressed as in many Aloninae (in Euryalona they are unusually long). The unmerged teeth on the postabdominal margin are also very different from most Aloninae, where they are either merged (like in the Hexalona-branch) or closely grouped (like in Coronatella-branch). In Salinalona, the teeth are quite separate, the groups hardly visible, and in Euryalona these are completely ungrouped. Again, the latter condition is more similar to Chydorinae than Aloninae. In other aspects, Salinalona has such strong modifications, as well as Euryalona, that phylogenetic relationships might be masked. For example, Salinalona has only six setae on the third limb, Euryalona has seven. The size reduction of the last seta on the fifth limb in Salinalona also occurs in Notoalona, where some species have lost it completely (Van Damme et al., 2013), but also in Alona this seta can be quite small as a result of expansion of the exopodite (Van Damme and Dumont, 2008b). In general, the exopodite surfaces in Salinalona are small, which indicates that this is not a benthic specialist (like the A. quadrangularis-group for example). Also the body shape is more fusiform, with a high head, the carapace is deeply concave and the antennal spines are nearly absent, which are also adaptations that suggest life in the open water or exposed littoral rather than inside detritus. Indeed, Salinalona species can survive in the open water of bays and estuaries, whereas most alonines prefer more sheltered, lentic conditions.

Some remnants of Chydorinae-like-features, and some similarities with a few of the most peculiar genera in the Aloninae, tempt us to speculate that Salinalona belongs to a basic lineage in the Chydoridae, perhaps even deriving from ancestors that originate from the split between the chydorid subfamilies. We can confirm, as Frey (1991) and Maiphae (2005) suggested, that $S$. taraporevalae and $S$. sarasinorum do not belong to Celsinotum or to Leberis, although a case could be made that there are certain similarities between these genera (mainly in reductions). However, we are certain that these taxa do not belong to Alona nor to any other known Aloninae genus. Instead, it seems that Salinalona gen.nov. is a separate lineage from most Aloni- 
nae, with a few characters linking it distantly even to the tropical genera Euryalona and to Notoalona, which deserves further exploration in the subfamily. From its morphology and the fact that this is a purely stenothermic lineage, it is most likely that the ancestor was tropical, not temperate, so this is not a neo-endemic deriving from Holarctic lineages, but a pure tropical Asian paleo-endemic (which is rare in the Anomopoda, as shown earlier). Even though the connections with other genera, based on the phenotype, is debatable and depends on the interpretation and the weights of morphological characters or character states, the main conclusion remains: Salinalona gen. nov. is a genus in its own right. Molecular data would be most useful to assess the phylogenetic position of this genus, but the number of molecular markers and the comparative framework for tropical chydorid species is at present too poor. Discussing its position further would make only sense in a (sub)family-wide phylogenetic context.

\section{Comment on Euryalona Sars, 1901}

As a comparative note, we included some observations in this study on the morphology of Euryalona orientalis (Daday, 1898), based on a population from Kalimantan, SE Asia. Even though Euryalona is a genus with unique morphology and a revision of this genus deserves a separate publication, some parallels with Salinalona prompted us to revise the limbs of Euryalona. Therefore, the results of that morphological exploration, allowing a few comments on this small tropical genus, are presented here as well, rather than in a separate contribution. This should hopefully be the first step to a future revision of the genus, with the delineation of new species. Euryalona was proposed by Sars (1901) and two species are presently recognised. Rajapaksa and Fernando (1987) provided a revision of this freshwater genus, which is confined to the southern hemisphere (Australia, Neotropics, Afrotropics, Oriental region), with notes on the limbs and concluded that Euryalona occidentalis Sars, 1901 and E. orientalis (Daday, 1898) were synonymous, suggesting only the latter and the Neotropical E. fasciculata Daday, 1905 as the two valid species. Following the latter revision, Kotov et al. (2013) listed Sars' (1901) Neotropical species as a junior synonym of E. orientalis. Are they synonyms, or has the morphology not been properly assessed? It is not unlikely that between tropical Asian and other tropical populations, significant differences can be found after taxonomical revision and the Asian populations could appear as valid species (Korovchinsky, 2013). Because our study represents the first detailed notes on Euryalona orientalis from tropical Asia since Rajapaksa and Fernando (1987), we include a few comments on the latter taxon as well as on the genus itself. Although a wider comparison of populations should be carried out for both E. occidentalis and E. orientalis in their respective regions and although a population from Borneo (Kaliman$\tan$ ) might not be representative for the species, we do think that the Neotropical and the Asian populations belong to two distinctly different species, in contrast to the conclusions by Rajapaksa and Fernando (1987), followed by subsequent authors.

Several differences between E. orientalis and E. occidentalis can be derived from existing descriptions, in combination with the new morphological observations presented herein. The postabdomen in E. orientalis is not as curved (postanal margin not as concave) as in E. occidentalis (Paggi, 1980; Rajapaksa and Fernando, 1987) and the antennal endopod in E. orientalis is much larger than the exopod (by half the length of the last endopod segment) (Rajapaksa and Fernando, 1987), whereas in E. occidentalis they both are of similar lengths (Sars, 1901; Paggi, 1980). The latter character is very obvious in most representations in the literature on both taxa and we therefore considered it to be a useful diagnostic in species separation (see key). For more differences between both, more populations in tropical Asia and in the Neotropics should be studied and revised at the same level, including limb features. The population from lake Tabiri (Borneo) studied here, might differ from E. orientalis, which was originally described from Sri Lanka. On the fourth limb for example, the specimens from Borneo have a distinctly long third exopodite seta, whereas Rajapaksa and Fernando (1987) depict a short seta (as long as the fourth seta) here on the true E. orientalis, whereas Smirnov (1974) also shows a long seta in this position on specimens from the White Nile, Africa. Therefore, it is possible, even likely, that there is more than one species currently lumped under E. orientalis, perhaps even in SE Asia. Until more populations are revised and studied, it is impossible to know and we should consider this as a species complex. There are a number of authors that also mention Euryalona from the Afrotropics (Gauthier, 1930), under either E. occidentalis or E. orientalis. The status of these populations is not known. Pending revision, the Afrotropical populations likely belong to a yet unnamed species of the genus, close to either of the latter species. Smirnov (1974) also includes E. brasiliensis Brehm and Thomsen, 1936 in his key, but the status of the taxon is unclear.

As for the morphology of the genus Euryalona, our brief examination revealed a few characters that escaped the attention of previous authors, especially on the limb endites. On the first limb, Euryalona has anterior setae that are well developed, which is considered as a basal state in the Aloninae (reduced for example in Coronatella or related genera) (Van Damme and Dumont, 2008a). It occurs in Notoalona as well, where these structures are even stronger modified (Van Damme et al., 2013). For the rest, the first limb has only two setae in the first endite 
and no basal seta below the ODL/IDL, which is present in most Aloninae (absent in Notoalona as well, for example) and the gnathobase is well developed with a single seta. The second limb is not peculiar, except for the absence of a seta on the exopodite, a few modified scrapers, and the elongated gnathobase. The latter, the elevated gnathobase, is also worth further exploration, as it also occurs in Notoalona, but otherwise it is rare in Aloninae. On the third limb, the exopodite has seven setae, of which the first two have a very strong forked arrangement, which is striking. The endites of this limb have well developed setae, but one seta on the inner row seems to be lacking (3'). We are not certain whether this is species-specific or a genus trait, or even aberrant for this population. The first two setae are very different from those in other Aloninae, which are always thicker, and this seems to be a unique state for Euryalona. The outer row of endite setae (1"'4 "') is extremely well developed - these setae are normally strongly modified and reduced in most Aloninae, but less so in Chydorinae. In this aspect, again, Euryalona seems to show some basal features. The fourth limb is highly peculiar in the endite because the flaming torch setae are not recognizable as such and do not have the typical strong wide basis and strong setules in the distal half (which actually makes a flaming torch seta), and also the gnathobase looks quite unusual. This kind of arrangement reminds of strongly modified flaming torch setae on the fourth limb in Anchistropus and Pseudochydorus (Van Damme and Dumont, 2007) and this could be related to the presence of the hook on the first limb. The inner endite setae (1"-3") are then again, well developed. The fifth limb lacks a developed gnathobase (no filter comb), which goes together with a reduction of the sixth limb, and has a strongly expanded margin on the exopodite. In general, the exopodites III-V are all large, which is a typical adaptation within the Chydoridae to benthic life, generating an oxygen stream, as in Leydigia (Fryer, 1968; Kotov, 2006). This is confirmed by the observations of Sars (1901), that Euryalona is predominantly a bottom dweller that lives in detritus.

\section{The second endemic genus in the Oriental region}

So far, a single endemic lineage of genus level was known from tropical Asia, or in fact, from the traditional zoogeographic region known as the Oriental region (Forró et al., 2008), the monotypic Indialona Petkovski, 1966. The latter genus is so aberrant that it has been assigned its own tribus in the Aloninae, based on limb morphology (Indialonini) (Kotov, 2000). In comparison to the Neotropical, the Nearctic, the Palaearctic and the Australian regions, the endemism and the diversity in the Oriental region at the genus level is low (one endemic genus out of 36 genera) (Forró et al., 2008). With Salinalona gen.nov., there are now two endemic genera in the region.
The relatively lower diversity and endemism could be natural, but it is more likely a result of the fact that large portions of tropical Asia and wider, of the Oriental region, as well as a wide range of habitats, remain unsampled (Korovchinsky, 2013; Van Damme et al., 2013). In addition, there is a taxonomical cryptic diversity to take into account: a significant chunk of the diversity remains ignored until species complexes or poorly known taxa have been properly revised. Such revisions lead to a more realistic idea on the cladoceran endemism and speciation in any given region. Because Alona is a large lumping genus (Van Damme et al., 2010), cryptic taxa of species- and even of genus rank can still be expected worldwide. Other examples of recently separated small Alona-like genera are Matralona Van Damme et Dumont, 2009 or the Australasian Armatalona Sinev, 2004 (Sinev, 2004; Van Damme and Dumont, 2009; Van Damme et al., 2010). Salinalona gen.nov. externally has an even more general Alona-morphotype than the former two taxa. Its recognition here as a non-Alona, has become only possible since the recent increase of taxonomical efforts in the Aloninae. Our understanding of the core Alona has changed and now benefits from a wide set of characters, for the first time in centuries (Van Damme and Dumont, 2008b; Van Damme et al., 2010). Salinalona gen.nov. has been largely overlooked because of its general Alona-like appearance and the absence of enough specimens for study (likely partly due to its peculiar habitat). From the existing lists of species from the region, it is unlikely that there are more such cryptic genera among the endemic Cladocera in tropical Asia, yet it can not be excluded that new taxa of this taxonomic level will be discovered as a result of more intense sampling efforts in the region.

From the above, it seems that the morphology of Euryalona, like Salinalona, is relatively specialised to accompany a specific niche, albeit unknown. The limbs in Euryalona also suggest a more ancestral origin than hitherto thought, and the relationships with other peculiar Aloninae such as Notoalona, deserve closer attention.

\section{An unusual (saline) habitat preference}

Salinalona gen. nov. has an unusual ecology for Chydoridae, in that it survives and even reproduces successfully under high salinities. We do not know the limits of tolerance in Salinalona, but this small lineage can be considered as an extremophile among waterfleas. There is an acute drop in cladoceran diversity above conductivities of $c a .5 \mathrm{mS}^{-\mathrm{cm}^{-1}}$ and $c a .10$ ppt salinity: the anomopods that can successfully reproduce above this range are mostly not chydorids (Frey, 1993b). In fact, very few chydorids can tolerate salinities above $15 \mathrm{ppt}$, with the exception of very few, such as the specialised Celsinotum (Frey, 1991), or taxa close to the A. elegansgroup such as Extremalona Sinev et Shiel, 2012 (Aus- 
tralia) or A. floessneri Sinev, Alonso et Sheveleva, 2009 (Uvs-Nuur, Mongolia) and A. salina Alonso, 1996 (Spain) (Sinev et al., 2009; Sinev and Shiel, 2012). Extremalona and Celsinotum can survive in non-alkaline, athalassic saline waters with low $\mathrm{pH}$ and have been described from Australia (Frey, 1991; Sinev and Shiel, 2012). In another branch of Alona-like chydorids, a peculiar species occurs in saline lakes at high altitudes in the Andes, Alona nigra Smirnov, 1996 (Kotov et al., 2010), unrelated to the A. elegans-group (to which the halotolerant $A$. floessneri and A. salina belong). Although the number of records of Salinalona remains very scarce, it is clear that this animal is well adapted to higher salinity ranges. It might be that the habitat is overlooked as well, for example, coastal peat swamps are not primarily the focus of zooplankton sampling campaigns (Van Damme et al., 2013). However, it is possible that Salinalona, even though it can perform in culture under normal conditions (as for salinity and feeding) (Shirgur and Naik, 1977), is unable to compete in nature with other chydorids in a low salinity, or freshwater setting. The saline environment may act as a niche, but equally as a refuge. The special adaptation of the first limb indicates the exploitation of a feeding niche within that particular environment. The halotolerance in Salinalona gen. nov. is high, not only for the live animals but also for the ephippia. It is euryhaline to such an extent that adults can successfully reproduce under a wide range of conductance, $\mathrm{pH}$ and salinity, and that the ephippia are formed and remain viable even under hypersaline conditions. The upper limits have never been tested. Frey (1991) noted that no chydorids are confined to thalassic waters, however - they are strictly a freshwater group and they expand their occurrence into saline waters according to the physiological tolerance and adaptations of the individual species. Only few chydorid species can survive over 15 ppt salinity (Frey, 1991, 1993b). The fact that the ephippia remain viable under saline conditions and that these species occur in bays and estuaries, opens the possibility of marine dispersal and implies mechanisms that differ from the majority of cladocerans in the resting stages as well. Indeed, S. sarasinorum is nearly exclusively found in coastal areas or on small islands, which can indicate overseas ephippial dispersal and the species seems unable to penetrate deeper inland. Shirgur and Naik (1977) collected ephippia of $S$. taraporevalae from Back bay (Bombay, India) at salinities of $26 \mathrm{ppt}$, which were viable. In the lab, they were able to hatch and culture the animals, kept between salinities of 1.5 and $18 \mathrm{ppt}$ - the animals thrived best at $7.5 \mathrm{ppt}$ (Shirgur and Naik, 1977), which is remarkable (Frey, 1991). Our findings in Southern Thailand indicate that Salinalona occurs in both freshwater and saline habitats. However, from our field samples it seems that the populations can be very large even when salinity is high, the opposite of what is expected in most Chydoridae. Often, Salinalona would be the only cladoceran in such samples. This could be well related to an adaptation to temporary systems, which reach high conductances and salinities when drying. Maikhao peat swamp for example, acted as an ephemeral system, at least for parts of the site and in recent years (Chittapun et al., 2005). As Frey (1991) quoted, cladoceran adaptations to strong fluctuations in ionic concentrations, can be a result of a long history of aridity in a given region. This is considered an important reason why Australia has several endemics that are adapted to higher salinities, such as Extremalona or Celsinotum (Frey, 1991; Sinev and Shiel, 2012), and this is likely the case for the Mongolian A. floessneri and the Iberian A. salina as well. Perhaps another evolutionary driving force behind such adaptations, at least in the tropical SE Asia, could be the fact that here, coastal ephemeral brackish peat swamps were much more extensive in the past, the current-day habitat only occupying a fraction of its former presence (Morley, 2013). The latter likely played a role in regional cladoceran speciation and peat swamp and swamp habitats are definitely overlooked in SE Asia for this group (Van Damme et al., 2013). Salinalona might have adapted in such coastal brackish ephemeral swamp systems, fluctuating between brackish and freshwater and back to the wide range of conditions $(\mathrm{pH}$, salinity, conductance) of the similar habitats it currently lives in (coastal swamps, estuaries).

\section{An important site for zooplankton diversity: Maikhao peat swamp, Phuket island}

We based the redescription of $S$. sarasinorum, the starting point of our study and of the delineation of Salinalona, mainly on specimens from Maikhao peat swamp in Phuket island, Thailand. Even though this might not be the most typical habitat for Salinalona as a predominantly freshwater swamp with a mainly freshwater cladoceran fauna, it is directly adjacent to the Andaman sea and therefore has increased salinity at times and retains a long resident population of S. sarasinorum. As stated earlier, this particular locality (Fig. 15) can be considered as significant to zooplankton studies in the region; in general, tropical peat swamps are important habitats for zooplankton diversity and speciation (Chittapun et al., 1999, 2005, 2007; Segers and Chittapun, 2001; Van Damme et al., 2013). At the same time, peat swamps in SE Asia are still underestimated in limnological surveys, their diversities poorly known, while being under strong human pressure (Chittapun et al., 2005; Van Damme et al., 2013), with a realistic risk of fragmentation and an entire habitat type disappearing, leading simply to the silent extinction of complete faunas. In 1999-2001, at the onset of our sampling, this locality was still pristine. After the tsunami in 2004 (26-11-2004) 
which struck Phuket's coastline hard, the locality was affected yet zooplankton communities seemed to restore (likely from dormancy rather than dispersal, which is possible shortly after disturbance) (Chittapun et al., 2005), even though for cladocerans, populations were not as abundant and the site was clearly disturbed and more eutrophic than before (SM, personal observation). However, the largest impact shortly after the end of 2004 might not have been the natural tsunami but the human tsunami, by the construction of a new hotel and a resort (Piraya resort) that have been built at the site, as well as a new road that cuts through the original peat swamp (Fig. 15), which is now significantly smaller and increasingly more polluted than a decade ago. We found and sampled a small original part of Maikhao peat swamp behind the new resort that still contains some of the original zooplankton fauna, yet it is currently unclear whether or when this last part will be destroyed due to further development, and with it, a diversity hotspot for zooplankton.

\section{CONCLUSIONS}

Maikhao peat swamp is just one example. Many peat swamps in SE Asia, or other large temporary freshwater systems, await or have undergone a similar fate due to human interference. For cladoceran studies, this habitat can be considered as important, worth studying and protecting (Van Damme et al., 2013; Van Damme and Sinev, 2013), not only in Thailand but in the whole SE Asia, where virtually nothing is known from this habitat. Conservation efforts for the SE Asian peat swamps have increased through the ASEAN Peatlands Forest Project, but the challenges are many (APFP, 2010-2013). If such localities cannot be protected directly in nature and risk irreversible change, then future zooplankton surveys could
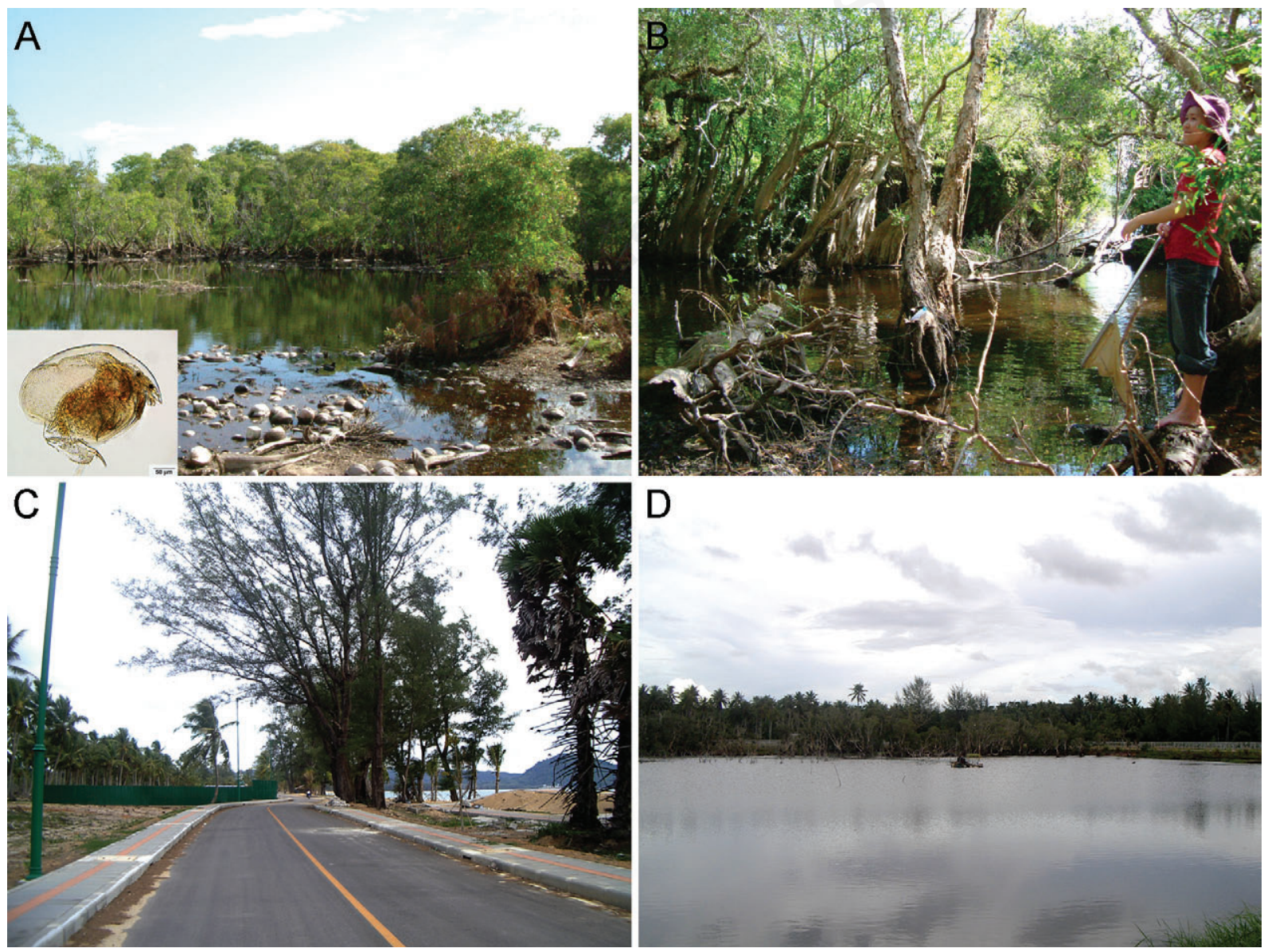

Fig. 15. Maikhao peat swamp, Phuket province, Thailand. A,B) The site in 11-01-2005, with still a (relatively) healthy appearance, yet already different since 2000, when Salinalona was collected. Inset in A) shows Salinalona sarasinorum from this site. Person shown in B) is Dr. S. Chittapun, sampling the rotifer fauna; C,D) same locality, 06-09-2006; C) newly constructed road cutting through the swamp; D) the ecosystem as it is now, with reduction of its vegetation and characteristics. The original swamp areas are strongly reduced. All photographs by SM. 
take into account that eggbanks, which can be easily collected, stored and later resurrected under controlled conditions for zooplankton groups with dormant stages, would constitute valuable dry (live) collections, in addition to the standard wet (dead) collections. The method has a wide range of advantages, yet is virtually unexplored (Sars method) (Van Damme and Dumont, 2010). The latter might be the only way forward to conserve the genetic diversity of zooplankton and larger branchiopod crustacean populations in the long term from disappearing habitats, in particular from diverse yet strongly fragmented habitats under threat, like the SE Asian peat swamps.

\section{Keys to species}

Key to the adult parthenogenetic females of Salinalona gen.nov.

1. Postabdomen with embayment near the basis of the terminal claw. Posteroventral valve corner without a notch. Antennal setae with well-developed apical spines Salinalona sarasinorum

(Stingelin, 1900) comb. nov.

Distribution: South East (SE) Asia (Malaysia, Indonesia, Philippines, Southern Thailand) and SE China.

2. Postabdomen lacking an embayment near the basis of the terminal claw or embayment very shallow. Posteroventral valve corner with a clear notch. Antennal setae with minute apical spines Salinalona taraporevalae (Shirgur et Naik, 1977) comb. nov. Distribution: Mumbai and Tamil Nadu, India.

Key to the adult parthenogenetic females of Euryalona Sars, 1901

1. Antennal setae of the first and second segments of the endopodite short, not reaching beyond the apex of the next segments, or just briefly (never half the length of the seta). Postabdomen moderately concave in postanal portion

Antennal setae of the first and second segments of the endopodite longer, both reaching beyond the apex of the next segments, the most distal seta for more than half its length. Postabdomen deeply concave in postanal portion ........Euryalona fasciculata Daday, 1905 (Neotropics).

Antennal endopodite much longer than the exopodite (by about half the length of the last endopodite segment) ...............Euryalona orientalis (Daday, 1898) (Australasia);

Antennal endopodite same length as the exopodite or just longer (never longer by about half the length of the last endopodite segment) ....................Euryalona occidentalis Sars, 1901 (Neotropics).

Note that both Euryalona orientalis (Daday, 1898) (Australasia) and Euryalona occidentalis Sars, 1901
(Neotropics) should be considered as species complexes; the Afrotropical populations await revision and could belong to $E$. orientalis or a new species.

\section{ACKNOWLEDGMENTS}

KVD participated in the Freshwater Invertebrates of the SE Asia Workshop (FISA Workshop) at Mahasarakham University, Thailand, 2012 and thanks the main organisers, Prof. Dr. La-orsri Sanoamuang and Dr. Maria K. Hołyńska, for the invitation and financial support. The meeting was sponsored by ASEAN-EU Science, Technology \& Innovation 2012; Faculty of Science, Mahasarakham University, Thailand; Applied Taxonomic Research Center, Khon Kaen University, Thailand; and Science Society of Thailand under the Patronage of His Majesty the King, Northeastern Branch. KVD also thanks the Algal and Plankton Society of Thailand for his study visit in 2010 at the Zooplankton Unit, Department of Biology, Prince of Songkhla University (PSU), where a large part of this work was carried out. SM and KVD would like to express thanks to Assoc. Prof. Pornsilp Pholpunthin, Department of Biology, PSU (Thailand) for his valuable advice and his support throughout this research. This work was supported by Thailand Research Fund (MRG4980039), the Higher Education Research Promotion and the National Research University Project of Thailand, Office of the Higher Education Commision of Thailand. The authors would also like to thank Em. Dr. H.J. Dumont, under whose supervision taxonomical efforts in Thai cladocerans were initiated at Ghent University, Belgium; Dr. F.D. Ferrari and Dr. C. Walter (National Museum of Natural History, Smithsonian Institution, USA), for allowing the study of the paratype of $A$. taraporevalae; and Dr. P. Frenzel for allowing the study of the holotype of $A$. sarasinorum from Stingelin's collection from the Naturmuseum Olten, Switzerland. The authors also thank Dr. N.M. Korovchinsky, Dr. A.Y. Sinev and Dr. I. Hudec for useful comments on this manuscript. Finally, we thank S. Fangcholjit, S. Mulmek and P. Sa-ardrit for help in sampling, and P. Meksuwan at the Zooplankton Unit, PSU, for various technical support.

\section{REFERENCES}

APFP, 2010-2013. Sustainable management of peatland forests in Southeast Asia: ASEAN Peatland Forests Project (APFP), SEApeat. Available from: http://www.aseanpeat.net/

Brehm V, 1933. [Mitteilungen von der Wallacea-Expedition Woltereck. Mitteilung VI. Die Alona- und Alonella-Arten von Dagiangan]. [Article in German]. Zool. Anz. 104:77-84.

Chatterjee T, Kotov AA, Van Damme K, Chandrasekhar SVA, Padhye S, (2013) (in press). An annotated checklist of the Cladocera (Crustacea: Branchiopoda) from India. Zootaxa.

Chittapun S, Pholpunthin P, Segers H, 1999. Rotifera from peatswamps in Puket province, Thailand, with the description of 
a new Colurella Bory de St. Vincent. Int. Rev. Hydrobiol. 84:587-593.

Chittapun S, Pholpunthin P, Segers H, 2005. Restoration of tropical peat swamp rotifer communities after perturbation: an experimental study of recovery of rotifers from the resting egg bank. Hydrobiologia 546:281-289.

Chittapun S, Pholpunthin P, Segers H, 2007. Diversity of rotifer fauna from five coastal peat swamps on Phuket island, Southern Thailand. ScienceAsia 33:1-5.

Forró L, Korovchinsky NM, Kotov AA, Petrusek A, 2008. Global diversity of cladocerans (Cladocera; Crustacea) in freshwater. Hydrobiologia 595:177-184.

Frenzel P, 1987. [Theodor Stingelin (1872-1932):Typen und Status seiner Cladoceren-Taxa]. [Article in German]. Arch. Hydrobiol. Suppl. 74:488-507.

Frey DG, 1991. A new genus of alonine chydorid cladocerans from athalassic saline waters of New South Wales, Australia. Hydrobiologia 224:11-48.

Frey DG, 1993a. Subdivision of the genus Pleuroxus (Anomopoda, Chydoridae) into subgenera worldwide. Hydrobiologia 262:133-144.

Frey DG, 1993b. The penetration of cladocerans into saline waters. Hydrobiologia 267:233-248.

Fryer G, 1968. Evolution and adaptive radiation in the Chydoridae (Crustacea: Cladocera): a study in comparative functional morphology and ecology. Philos. T. Roy. Soc. B 254:221-382.

Gauthier H, 1930. [Mission saharienne Augiera-Draper 19271928, Cladocères, Ostracodes, Phyllopodes, Anostracés et Conchostracés]. [Article in French]. Bull. Mus. Hist. Nat. Paris 2:92-116.

Idris BAG, 1983. Freshwater zooplankton of Malaysia (Crustacea: Cladocera). Perenbit University ed., Pertanian: 153 pp.

Idris BAG, Fernando CH, 1981. Cladocera of Malaysia and Singapore with new records, redescriptions and remarks on some species. Hydrobiologia 77:233-256.

Korovchinsky NM, 2013. Cladocera (Crustacea: Branchiopoda) of South East Asia: history of explorations, taxon richness and notes on zoogeography. J. Limnol. 72(Suppl.2):e7.

Kotov AA, 2000. Redescription and assignment of the chydorid Indialona ganapati Petkovski, 1966 (Branchiopoda: Anomopoda: Aloninae) to Indialonini, new tribus. Hydrobiologia 439:161-178.

Kotov AA, 2006. Adaptations of Anomopoda crustaceans (Cladocera) the the benthic mode of life. Entomological Review 86:S210-S225.

Kotov AA, Forró L, Korovchinsky NM, Petrusek A, 2013. World checklist of freshwater Cladocera species. Available from: http://fada.biodiversity.be/group/show/17

Kotov AA, Sinev AY, Berrios VL, 2010. The Cladocera (Crustacea: Branchiopoda) of six high altitude water bodies in the North Chilean Andes, with discussion of Andean endemism. Zootaxa 2430:1-66.

Kotov AA, Van Damme K, Bekker EI, Siboualipha S, Silva-Briano M, Adabache Ortiz A, Galvan de la Rosa R, Sanoamuang L, 2013. Cladocera (Crustacea: Branchiopoda) of Vientiane province and municipality, Laos. J. Limnol. 72(Suppl.2):e6.

Maiphae S, 2005. Taxonomy and biogeography of the Cladocera from Southern Thailand, with specific reference to Alona
Baird,1843 and Macrothrix Baird, 1843. PhD Thesis. Prince of Songkla University ed., Hat Yai: 314 pp.

Maiphae S, Pholpunthin P, Dumont HJ, 2008. Taxon richness and biogeography of the Cladocera (Crustacea, Ctenopoda, Anomopoda) of Thailand. Ann. Limnol.-Int. J. Lim. 44:33-43.

Michael RG, Sharma BK, 1988. Fauna of India and adjancent countries. Indian Cladocera (Crustacea: Branchiopoda: Cladocera). Zoological Survey of India ed., Calcutta: 262 pp.

Morley R, 2013. Cenozoic ecological history of South East Asian peat mires based on comparison of coals with present day and Late Quaternary peats. J. Limnol. 72(Suppl.2):e3.

Paggi JC, 1980. [Aportes al conocimiento de la fauna Argentina de Cladóceros. II. Euryalona fasciculata Daday, 1905 y Euryalona occidentalis Sars, 1901]. [Article in Spanish]. Rev. Asoc. Cienc. Nat. Litoral. 11:91-114.

Rajapaksa R, Fernando CH, 1987. A redescription of Euryalona orientalis (Daday, 1898), with a consideration of the other species in the genus Euryalona (Cladocera: Chydoridae). Hydrobiologia 150:75-90.

Sars GO, 1901. Contributions to the knowledge of the freshwater Entomostraca of South America, as shown by artificial hatching from dried material. Arch. Math. Naturvidensk. 23:1-102.

Segers H, Chittapun S, 2001. The interstitial Rotifera of a tropical freshwater peat swamp on Phuket island, Thailand. Belg. J. Zool. 131:65-71.

Sharma BK, Michael RG, 1984. Redescription of Alona taraporevalae Shirgur \& Naik, 1977 (Cladocera; Chydoridae: Aloninae). Rec. Zool. Surv. India 81:35-39.

Shirgur GA, Naik AA, 1977. Observations on morphology, taxonomy, ephippial hatching and laboratory culture of a new species of Alona (Alona taraporevalae Shirgur \& Naik), a chydorid cladoceran from Back bay, Bombay. Spec. Publ. Nat. L. Inst. Oceanogr., pp. 48-59.

Silva-Briano M, Dumont HJ, 2001. Wlassicsia, Bunops \& Onchobunops (Anomopoda), three related genera. Hydrobiologia 442:1-28.

Sinev AY, 2004. Armatalona gen.n. - a new genus of subfamily Aloninae (Anomopoda, Chydoridae), separated from genus Alona Baird, 1840. Hydrobiologia 520:29-47.

Sinev AY, Alonso M, Sheveleva NG, 2009. New species of Alona from South-East Russia and Mongolia related to Alona salina Alonso, 1996 (Cladocera: Anomopoda: Chydoridae). Zootaxa 2326:1-23.

Sinev AY, Shiel R, 2012. Extremalona timmsi gen. nov., sp. nov., a new cladoceran (Cladocera: Anomopoda: Chydoridae) from an acid saline lake in southwest Western Australia. J. Nat. Hist. 46:2845-2864.

Sinev AY, Van Damme K, Kotov AA, 2005. Redescription of tropical-temperate cladocerans Alona diaphana King, 1853 and Alona davidi Richard, 1895 and their translocation to Leberis Smirnov, 1989 (Branchiopoda: Anomopoda: Chydoridae). Arthropoda Sel. 14:183-205.

Smirnov NN, 1971. Morpho-functional grounds of mode of life of Cladocera. V. Morphology and adaptive modifications of trunk limbs of Anomopoda. Hydrobiologia 37:317-345.

Smirnov NN, 1974. [Chydoridae of the world. Israel Program for Scientific Translations, Jerusalem, 1974]. [Book in Russian]. Nauka, Leningrad: 531 pp.

Smirnov NN, 1998. A revision of the genus Camptocercus 
(Anomopoda, Chydoridae, Aloninae). Hydrobiologia 386:63-83.

Smirnov NN, 1999. Morpho-functional grounds of life mode of "Cladocera". X. Specialized "Cladocera" (Phyllopoda: Crustacea) as victims of morphological radiation. Arthropoda Sel. 8:35-41.

Stingelin T, 1900. [Beitrag zur Kenntnis der Süsswasserfauna von Celebes. Entomostraca]. [Article in German]. Rév. Suisse Zool. 8:193-207.

Van Damme K, Dumont HJ, 2006. Sex in a cyclical parthenogen: mating behaviour of Chydorus sphaericus (Crustacea; Branchiopoda; Anomopoda). Freshwater Biol. 51:2334-2346

Van Damme K, Dumont HJ, 2007. Limb morphology of the carnivorous anomopods Anchistropus emarginatus Sars, 1862 and Pseudochydorus globosus (Baird, 1843) (Crustacea: Branchiopoda: Anomopoda). Ann. Limnol.-Int. J. Lim. 43:271-284.

Van Damme K, Dumont HJ, 2008a. Further division of Alona Baird, 1843: separation and position of Coronatella Dybowski \& Grochowski and Ovalona gen. n. (Crustacea: Cladocera). Zootaxa 1960:1-44.

Van Damme K, Dumont HJ, 2008b. The 'true' genus Alona Baird, 1843 (Crustacea: Cladocera: Anomopoda): characters of the A. quadrangularis-group and description of a new species from Democratic Republic Congo. Zootaxa 1945:1-25.

Van Damme K, Dumont HJ, 2009. Notes on chydorid endemism in continental Africa: Matralona gen. n., a monotypic Alo- nine from the Fouta Djalon Plateau (Guinea, West Africa) (Crustacea: Cladocera: Anomopoda). Zootaxa 2051:26-40.

Van Damme K, Dumont HJ, 2010. Cladocera of the Lençóis Maranhenses (NE-Brazil): faunal composition and a reappraisal of Sars' Method. Braz. J. Biol. 70:755-779.

Van Damme K, Eggermont H, 2011. The Afromontane Cladocera (Crustacea: Branchiopoda) of the Rwenzori (UgandaD.R. Congo): taxonomy, ecology and biography. Hydrobiologia 676:57-100.

Van Damme K, Kotov AA, Dumont HJ, 2010. A checklist of names in Alona Baird 1843 (Crustacea: Cladocera: Chydoridae) and their current status: an analysis of the taxonomy of a lump genus. Zootaxa 2330:1-63.

Van Damme K, Maiphae S, Sa-ardrit P, 2013. Inland swamps in South East Asia harbor hidden cladoceran diversities: species richness and the description of new paludal Chydoridae (Crustacea: Branchiopoda: Cladocera) from Southern Thailand. J. Limnol. 72(Suppl.2):e10.

Van Damme K, Sinev AY, 2013. Tropical Amphi-Pacific disjunctions in the Cladocera (Crustacea: Branchiopoda). J. Limnol. 72(Supp1.2):e11.

Van Damme K, Sinev AY, Dumont HJ, 2011. Separation of Anthalona gen. n. from Alona Baird, 1843 (Branchiopoda: Cladocera: Anomopoda): morphology and evolution of scraping stenothermic alonines. Zootaxa 1875:1-64.

Venkataraman K, 1999. Freshwater Cladocera (Crustacea) of Southern Tamil Nadu. J. Bomb. Nat. Hist. Soc. 96:268-280. 